NBER WORKING PAPER SERIES

\title{
CAPITAL FLOWS, REAL ESTATE, AND LOCAL CYCLES: EVIDENCE FROM GERMAN CITIES, BANKS, AND FIRMS
}

\author{
Peter Bednarek \\ Daniel Marcel te Kaat \\ Chang Ma \\ Alessandro Rebucci \\ Working Paper 26820 \\ http://www.nber.org/papers/w26820
NATIONAL BUREAU OF ECONOMIC RESEARCH
1050 Massachusetts Avenue
Cambridge, MA 02138
March 2020

For comments and discussions, we are grateful to Alina Arefeva, Natalija Barasinska, Valeriya Dinger, Sebastian Doerr, Vadim Elenev, Giovanni Favara, Pedro Gete, Isaac Hacamo, Jia He, Zhiguo He, Mathias Hoffman, Deniz Igan, Yang Jiao, Matt Kahn, Sebnem Kalemli-Ozcan, Bo Li, Paula Margaretic, Daniel McMillen, Emi Nakamura, Luis Quintero, Vincenzo Quadrini, Tom Schmitz, Kilian Uber, Jerome Vandenbussche, Ko Wang, Cheng Xu, Jing Yang, Albert Zevelev, Sili Zhou, Tingyu Zhou. We also thank conference participants at the 2020 ASSA Meeting (IBEFA Session), 2019 ABFER Conference, 2019 AREUEA Annual National Meeting, 2019 AsRes Conference, the 2019 Autumn Forum on the Globalization of Real Estate Markets at the University of Zurich, the 1st FISF Real Estate Finance Workshop, the 2019 CCER Summer Institute, the 2019 CEPR AMCM conference, 2019 CEPR ESSIM, 2019 CICF, 2019 IMF Annual Macro-Financial Conference, 2019 Santiago Finance Workshop, as well as seminar participants at the Bundesbank, IMF, IWH Halle, Federal Reserve Board, and USC. Rebucci gratefully acknowledges the financial support of the Johns Hopkins Catalyst Award Program. The usual disclaimer applies. The views expressed in this paper do not reflect the ones of the Deutsche Bundesbank. The views expressed herein are those of the authors and do not necessarily reflect the views of the National Bureau of Economic Research.

NBER working papers are circulated for discussion and comment purposes. They have not been peer-reviewed or been subject to the review by the NBER Board of Directors that accompanies official NBER publications.

(C) 2020 by Peter Bednarek, Daniel Marcel te Kaat, Chang Ma, and Alessandro Rebucci. All rights reserved. Short sections of text, not to exceed two paragraphs, may be quoted without explicit permission provided that full credit, including $\odot$ notice, is given to the source. 
Capital Flows, Real Estate, and Local Cycles: Evidence from German Cities, Banks, and Firms Peter Bednarek, Daniel Marcel te Kaat, Chang Ma, and Alessandro Rebucci

NBER Working Paper No. 26820

March 2020

JEL No. D22,D53,E22,E3,E44,F3,G01,G15,G21,R3

\begin{abstract}
$\underline{\text { ABSTRACT }}$
We study how an aggregate bank flow shock impacts German cities' GDP growth depending on the state of their local real estate markets. Identification exploits a policy framework assigning refugees to cities on a quasi-random basis and variation in non-developable area for the construction of a measure of exposure to local real estate market tightness. We estimate that the German cities most exposed to real estate market pressure grew 2.5-5.0 percentage points more than the least exposed ones, cumulatively, during the 2009-2014 period. Bank flow shocks shift credit to firms with more collateral. More collateral also leads firms to hire and invest more in response to these shocks.
\end{abstract}

Peter Bednarek

Deutsche Bundesbank

Postfach 100602

Frankfurt am Main 60006

Germany

peter.bednarek@bundesbank.de

Daniel Marcel te Kaat

University of Groningen

Nettelbosje 2

Groningen 9747 AE

Netherlands

d.m.te.kaat@rug.nl

\author{
Chang Ma \\ Fanhai International School of Finance \\ Fudan University \\ Shanghai, China 200433 \\ machang.china@gmail.com \\ Alessandro Rebucci \\ Johns Hopkins Carey Business School \\ 100 International Drive \\ Baltimore, MD 21202 \\ and NBER \\ arebucci@jhu.edu
}




\section{Introduction}

It is well know that capital flows are procyclical at business cycle frequency and comove positively with asset prices. As an asset class, real estate is also procyclical and has a large weight in economies' income and wealth (Davis and Van Nieuwerburgh (2015)). Not surprisingly, a large macroeconomic literature shows that capital inflows are correlated with outcomes in housing and good markets. Empirical evidence on the causal effects of capital flow shocks on property prices and output, however, has proven elusive to establish relying on cross-country variation in the data, let alone documenting the transmission mechanisms to the receiving economy.

In this paper, we exploit the differential exposure of German cities to tightness in local real estate markets to quantify the causal effect of a capital flow shock on output growth via property prices, during the post-global financial crisis (GFC) episode of bank repatriation of foreign assets from Southern Europe. By doing so, we connect two large and important strands of the literature: one that studies the relationship between capital flows, house prices and output by relying on cross-country variation in the data, or on the calibration of DSGE models on individual economies -e.g., Aizenman and Jinjarak (2009), Cesa-Bianchi et al. (2018) Jordà, Schularick and Taylor (2017), and Favilukis et al. (2017); the other that exploits regional or local variation to establish causal effects of credit supply and house price shocks on real outcomes-e.g., Adelino et al. (2015), Chaney, Sraer and Thesmar (2012), Favara and Imbs (2015), Gan (2007), and Mian, Sufi and Verner (2017) among others.

We find that the impact on annual GDP growth of a bank flow shock, as captured by the sovereign bond spread of Southern European countries over Germany (the so-called GIPS spread), is more significant in cities that are more exposed to pressure in local commercial real estate markets. Moreover, we show that this differential impact can be wholly accounted for by commercial property price changes triggered by the bank inflow shock that we identify. We estimate that, in cities most exposed to real estate market tightness, real GDP grew 40-80 basis points more per year than in the least exposed ones, or 2.5-5 percentage points cumulatively during the 2009-2014 period. 
Figure 1 MACROECONOMIC BACKGROUND

Panel A: Real GDP (Index 2009:Q1=100)

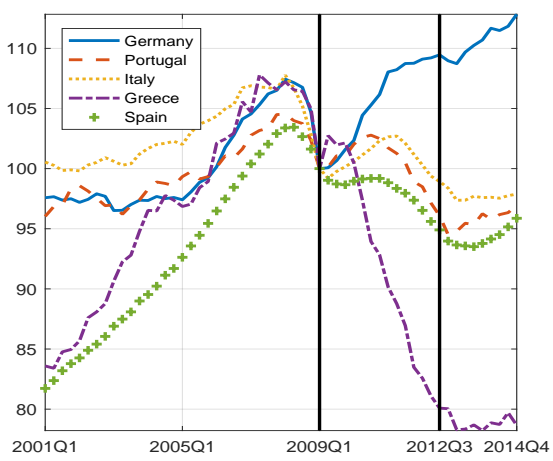

Panel C: Credit by Borrower (\% of Total)

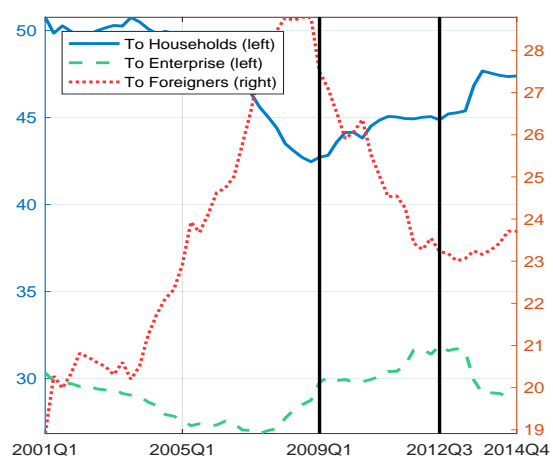

Panel E: Residential Real Estate (Indexes, 2009=100)

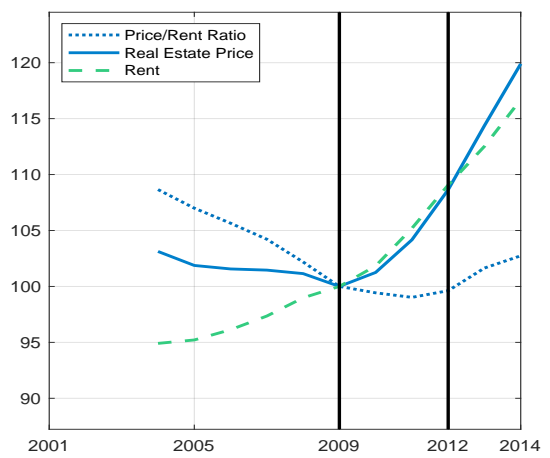

Panel B: VIX index, GIPS Spread and German Bund Yield

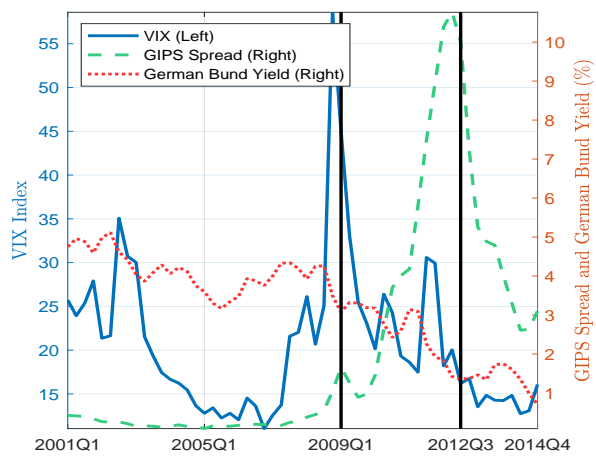

D: Total Domestic Credit by Type of Bank (\% GDP)

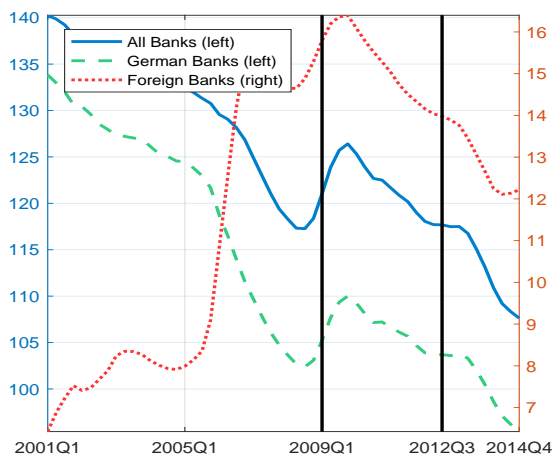

Panel F: Commercial Real Estate (Indexes, 2009=100)

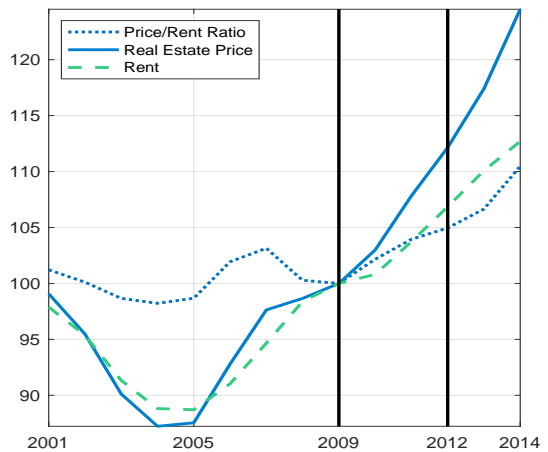

NotE. Panel A plots real GDP for Germany, Portugal, Italy, Greece and Spain. Panel B plots the US VIX index together with the GIPS Spread and the 10-year German Bund yield. Panel C plots the share of total lending by German banks to different borrowers. Panel D plots total credit as a share of GDP extended by different type of banks. Panel E and F plot, respectively, national residential and commercial real estate prices, rent and price-to-rent indexes. Residential data are not available from 2001-2003. The vertical lines mark the beginning of the German recovery in 2009:Q1 and the "Whatever It Takes" speech by ECB Governor Draghi in 2012:Q3, respectively. See the Data Appendix for variable definitions and data sources. 
Germany during the post-GFC period is an ideal laboratory to investigate the causal impact of capital flows on property prices and output. Before the GFC, German and other Northern European banks built up claims on the periphery that were far in excess of their respective countries' bilateral surpluses (Hale and Obstfeld (2016)). After the GFC, they reduced cross-border holdings of sovereign debt and increased their holdings of locally issued debt (Brutti and Sauré (2016)). As Figure 1 shows, post-GFC, Germany strongly outperformed Southern Europe in terms of real GDP growth (Panel A), as Portugal, Italy, Spain and Greece were engulfed in a deep and persistent sovereign debt and banking crisis (Panel B). Banks rebalanced the composition of their loan portfolios toward domestic households and firms by reducing exposure to foreigners (Panel C). Meanwhile, long-term interest rates fell dramatically (Panel B), the stock market soared (not reported), and Germany experienced the first property price boom in 20 years, with a cumulative real increase exceeding 20 percent in both the residential and the commercial sector during the 2009-2014 period (Panels E and F).

To investigate the transmission of capital flow shocks to city output growth via real estate markets, we assemble a new database that includes aggregate, city-level and bank-firm-level data described in detail in Section 2. At the aggregate level, we focus on bank flow data, based on BIS Locational Statistics, which is an important component of total capital flows (Bruno and Shin (2014)). Next, we construct a new matched city-level data set that, in addition to publicly available variables, includes a proprietary database on residential and commercial property price indexes from Bulwiengesa AG (a reputable German real estate data provider) and detailed city land use data. Last, to unpack the transmission mechanism through the commercial real estate sector, we construct a second novel bank-firm relationship level data set based on the German credit register, the Bundesbank supervisory database, and Bureau van Dijk's Amadeus.

To establish causation, we rely on identification by geographic variation. We first establish that, during our sample period, the GIPS spread is closely associated with alternative measures of bank flows from the rest of the euro area, and particularly with banks' repatriation of gross foreign assets. ${ }^{1}$ We show that this link is tight both at the aggregate level and the level of individual

\footnotetext{
${ }^{1}$ A recent literature has argued that global factors, such as the risk appetite of global financial intermediaries or the monetary policy conditions in the United States, have become increasingly important drivers of capital flows and asset prices across countries and broad asset classes-e.g., Rey (2013)-and uses the VIX index of stock market volatility,
} 
bank flows. We also show that the GIPS spread is associated with lower domestic lending-deposit spreads at the aggregate level and with lower firm borrowing costs at the firm level. This preliminary finding is consistent with the notion that, when banks repatriate foreign assets, they expand domestic credit supply. It is also in line with the macroeconomic evidence in Panel C of Figure 1 showing the changed composition of credit after the GFC. We then interact the GIPS spread, as a proxy for bank inflows from Southern Europe, with an ex-ante measure of real estate market tightness that varies across cities quasi-randomly and is kept constant over time at its pre-sample value in 2008 .

Our exposure measure is the product of two variables: the city share of refugees in total refugees and a city measure of non-developable area, both evaluated at their pre-sample values in 2008. The share of refugees in total refugees (henceforth the "share of refugees"), which is a novel instrument in the real estate literature, is a good candidate instrumental variable because it exploits features of a German policy framework that assigns refugee immigrants to cities on a quasi-random basis with respect to the business cycle. As we document in Section 3.2 of the paper, in Germany, refugees are allocated to cities following rules and regulations with criteria that are not affected by the business cycle because they are linked to population size. In the paper, we also document that refugees have limited or no ability to impact the labor market in the short-term in the case of Germany because they don't integrate easily due to language barriers and labor market legislation that naturally favors domestic residents and European nationals.

Yet, refugee immigrants can have a strong impact on local real estate markets, especially in the commercial sector. As in other countries, in Germany, refugees are entitled to housing benefits and are initially allocated in accommodation centers. As they have difficulties to integrate in the labor markets, many remain housed in public facilities well past reaching status and obtaining a work permit in Germany, even though some find accommodations in the private rental market, either independently or with government-provided vouchers. As we illustrate in a simple model of local commercial and residential real estate markets, refugees can put direct pressure on the existing supply of commercial real estate services for other productive uses and hence commercial

plotted in Panel B of Figure 1, as a driver of global bank flows. In a similar vein, we use the GIPS spread as a way to characterize regional bank flows. However, to establish causation, we interact it with an exposure measure of local real estate market tightness. 
Figure 2 Exposure And Average Property Price Changes

Residential Sector

Panel A: Exposure (corr=21\%, p-value=7\%)

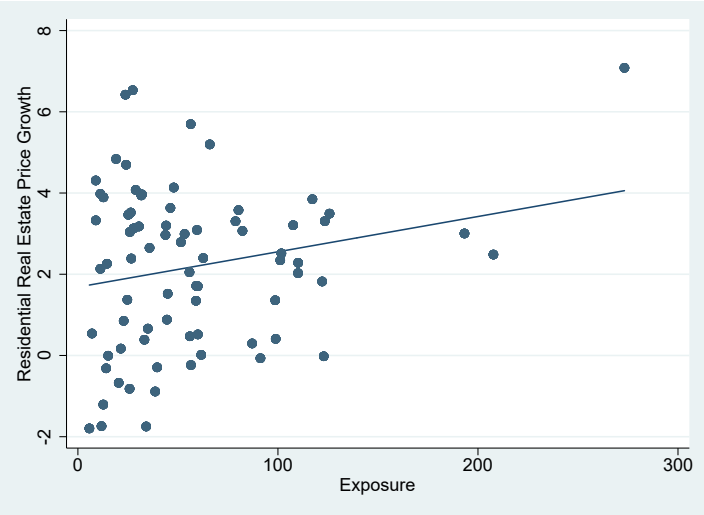

Commercial Sector

Panel B: Exposure (corr $=40 \%$, p-value $=0)$

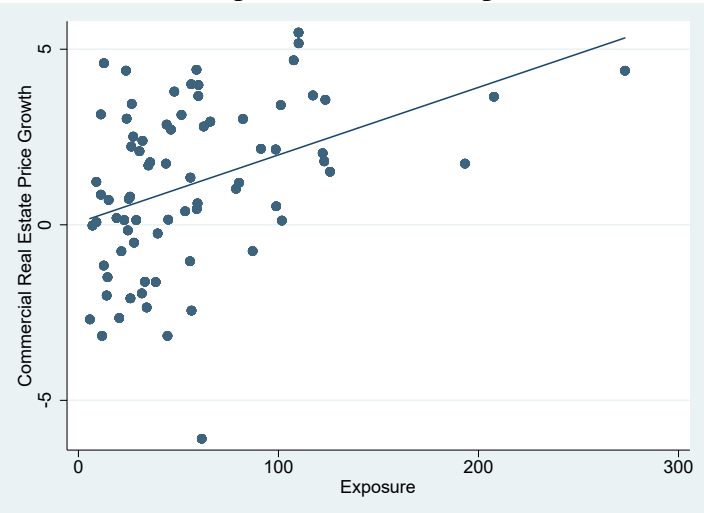

NOTE. The figure plots the relationship between city-level property price changes, averaged over the 2009-2014 period, and the 2008 value of our exposure measure, in both the commercial and the residential sector. See the Tables A.1 and A.4 in Appendix for details on variable definitions and all city values of the exposure measure and its components.

property prices. Indeed, in the paper we will show that, in the commercial sector, our exposure measure is a very good predictor of commercial property prices, as also visible at naked eye from Figure 2. In Germany, a very small minority of refugees rents in the open market once they reach status. Under certain circumstances, German cities provide vouchers for housing services in the rental market also for refugees who continue to be on welfare after reaching status. Refugees, therefore, could also put some direct pressure on the supply of residential real estate services.

As we show in our model, however, the sign of the impact of a higher city share of refugees on residential property prices is ambiguous. As our model in Appendix shows, this can be the case because a lower supply of commercial real estate services caused by higher share of refugees can curtail output and consumption of residents, and hence lowers a much larger component of the local demand of residential services. Moreover, higher taxes possibly needed to pay for refugee benefits could also put additional downward pressure on resident demand for housing. In our model, the net effect of a higher city share of refugees depends on parameter values, and is negative for a plausible parametrization consistent with the institutional details of the German policy framework and some of the stylized facts of our data. Interestingly, the evidence of a weaker relevance of our exposure measure for residential property prices that we document Section 4 of the 
paper, and the neighborhood-level evidence for the city of Hamburg in Dehos and Eilers (2018), are consistent with these model dynamics. For this reason, and to be able to asses the relative importance of the residential and commercial sectors in the transmission of the bank flow shock, in the paper, we also propose an alternative instrument for residential property prices, based on demographics, which we will discuss in more details below.

To control for city-level real estate supply, we interact the share of refugees with a measure of supply elasticity due to geography and land-use regulation in the spirit of Saiz (2010). The indicator that we use is the ratio of city land that cannot be developed to the total built-up area in 2008 (henceforth the share of non-developable area or land share for brevity). Unlike in the United States, in Germany, city variation in the incidence of steep-slope terrains and water bodies has a more limited impact on the distribution of non-developable area across German cities (OECD (2017)). Moreover, in Germany, land-use regulations are distributed more uniformly than in the United States (Schmidt and Buehler (2007)). Indeed, in the paper, we will argue that both components of our exposure measure are plausibly distributed quasi-randomly across cities, but neither of them predicts property prices as well as the interaction of the two, especially in the commercial sector.

The main result of the paper is that bank flow shocks, as captured by changes in the GIPS spread, have a larger impact on output growth in cities with tighter commercial real estate markets, as proxied by our exposure measure. Moreover, when we horse race the residential sector against the commercial sector by introducing both price indexes in our econometric model, we find strong evidence that the commercial sector dominates, and residential property prices have no significant effect on output growth in response to the capital flow shock in Germany. ${ }^{2}$ As a result, the city output growth differential identified in the reduced form estimate can entirely be accounted for by the different response of commercial property prices across cities triggered by the GIPS spread increase. We estimate that, during the 2009-2014 period, for every 100-basis points increase in the GIPS spread, cities at the 75 percentile of the exposure distribution grew 11-22 basis points more per year than cities at the 25th percentile. Given an average increase in the GIPS spread

\footnotetext{
${ }^{2}$ We are agnostic on the interpretation of this finding, but note that, unlike the case of the United State and other countries in which household debt rose sharply together with house prices, the German housing boom was not associated with a credit boom, at least through the end of our sample period-see, for example, Panel D of Figure 1.
} 
over our sample period of 360 basis points, these estimates imply that the cities most exposed to commercial real estate market pressure grew 39.6-79.2 basis points more per year than the least exposed cities, or 2.4-4.8 percentage points more cumulatively during the 2009-2014 period.

In light of the finding that, during the episode of bank retrenchment that we study, the residential sector does not appear to have played an important role, in the second part of the paper, we only investigate the role of the commercial sector in the transmission of our bank flow shock. When we unpack the transmission mechanism, we find that firms with more real estate collateral, as measured by tangible fixed assets, receive more credit when banks repatriate foreign assets and retrench from Southern Europe. Firms with more collateral also invest and hire more, thereby contributing to higher output growth. During the episode that we study, however, we find no evidence that better credit access and higher investment by firms with more real estate collateral leads to capital misallocation. ${ }^{3}$ Overall, the evidence in the second part of the paper is consistent with the working of a collateral channel on the firm side-e.g., Liu, Wang and Zha (2013), Chaney et al. (2012)), Gan (2007), Schmalz et al. (2017), Adelino et al. (2015) among others.

Literature Review Our paper relates to the literature along multiple dimensions. First, our paper connects to the literature on the relationship between capital flows, the business cycle and house prices based on cross-country evidence or DSGE models of individual economies-see Favilukis, Kohn, Ludvigson and Van Nieuwerburgh (2013) for a survey of both the theory and evidence. Our main contribution here is to identify the causal effect of a capital flow shock on short-term output growth via real estate markets by exploiting city variation in the data. As far as we are aware, this is the first paper that documents empirically the mediating role of property prices in the transmission of capital flow shocks in a causal manner. For example, Aizenman and Jinjarak (2009) document a strong positive association between the current account (i.e., net capital flows) and house prices, holding constant certain characteristics in a large panel of countries. We document a similarly close association between bank flows and property prices, but we establish causation. Cesa-Bianchi et al. (2015) and Cesa-Bianchi, Ferrero and Rebucci (2018) show that residential house prices comove strongly with consumption growth conditional on a bank flow shock iden-

\footnotetext{
${ }^{3}$ Again, while we are ultimately agnostic about this finding, it could be also elated to the fact that the German postGFC real estate boom is not associated with a credit boom, but rather an episode of retrenchment or flight-to-safety.
} 
tified in the time-series dimension of the country panel and relate consumption sensitivity to the shock with different country characteristics. We exploit the quasi-random variation of our real estate market exposure to assess causally the differential impact of a bank flow shock across cities in one advanced open economy. Moreover, unlike most of the empirical literature on capital flows and the business cycle, with Forbes and Warnock (2012) being one of a few exceptions, we investigate an episode of capital "retrenchment". Favilukis, Ludvigson and Van Nieuwerburgh (2017) study theoretically the impact of capital flows into the United States and show that lower bond yields associated with inflows of foreign capital cannot explain the US residential house price boom. We distinguish between the commercial and the residential real estate sectors and provide disaggregated evidence that firms' real estate collateral introduces additional channels of transmission of capital flow shocks. Moreover, we find evidence consistent with Favilukis, Ludvigson and Van Nieuwerburgh (2017) that residential property prices are not part of the transmission mechanism. Caballero and Simsek (forthcoming) develop a model of transmission of a capital flow shock originating from repatriation of foreign assets, as in our empirical analysis. We provide direct evidence speaking to these dynamics.

Second, the paper relates to the literature on the link between capital flows, credit, the real economy and house prices that exploits regional variation in the data. Employing bank-firm level data from the Turkish credit registry, Baskaya, Giovanni, Kalemli-Ozcan and Ulu (2018) show that capital inflows increase the volume and reduce the price of domestic credit. We provide similar evidence using credit register data for a major advanced economy and also evaluate the transmission mechanism to house prices and firm outcomes, including misallocation. Mian, Sufi and Verner (2017) show that an aggregate credit supply shock boosts local demand and amplifies the expansion phase of the business cycle in the United States, with higher GDP, employment, residential investment, and house prices. We document comparable dynamics for Germany, but explore the transmission mechanism at the bank-firm level. Giroud and Mueller (2018), also employing an identification strategy by geographic variation, show that leverage buildups by large US publicly listed firms lead to boom-bust cycles in employment, with a short-run expansion and a medium-term contraction. While we find consistent evidence on the city response of German employment to the capital flow shock, we do not distinguish between short and medium-term 
effects. Cetorelli and Goldberg (2012) show that global banks contracted their direct and indirect cross-border lending during the GFC, leading to a reduction in credit supply in regions from which capital was pulled. We study the complementary case of a country whose banks repatriated foreign assets during and after the GFC and establish that bank retrenchment led to an increase in domestic credit supply, benefiting especially firms that are richer in real estate collateral.

Our paper also relates to the large theoretical and empirical literature on the collateral channel and real estate prices. The underlying mechanism is that agents use pledgeable assets as collateral, typically land and buildings, to finance productive projects, residential housing and durable consumption. Fluctuations in property prices, therefore, can have sizable effects on aggregate investment, consumption and output, as our model in the Appendix also suggests. Iacoviello (2005) and Liu, Wang and Zha (2013) develop closed-economy DSGE models of the collateral channel on the household and the firm side, respectively, estimated with US data. Liu et al. (2013), in particular, introduce land in the firm borrowing constraint and show that the model can explain the comovement between land prices and business investments; a correlation that the collateral channel from the household side cannot match. We show that commercial property price changes triggered by bank flow shocks can account for all the differential impact of these shocks on city output growth, thus providing more granular evidence consistent with the working of a collateral channel on the firm side. Chaney, Sraer and Thesmar (2012) use US firm-level data to show that an exogenous variation in property prices triggered by aggregate mortgage rate changes can have a sizable impact on corporate investment. Using comparable data and methodology, we find that these effects are quantitatively sizable in the transmission of bank flow shocks. Moreover, we horse race residential and commercial property prices and show that, unlike the case in the United States, the commercial sector dominates and residential property prices do not affect the transmission. Other studies with micro data show that fluctuations in property prices can also have an impact on firm employment, exit and entry decisions, and capital structure (e.g., Schmalz, Sraer and Thesmar (2017), Cvijanović (2014)), respectively). We provide micro evidence on the transmission mechanism of bank flow shocks through similar effects on firm hiring and investment decisions and total factor productivity.

The paper speaks to the new literature on the role of foreign purchases in global cities like Lon- 
don, New York and Vancouver. Favilukis and Van Nieuwerburgh (2017) develop a heterogeneous spatial model of cities and show that an increase in out-of-town home buyers can drive up local real estate prices significantly. Consistent with their findings, we show that influxes of refugee immigrants can predict property prices in the commercial sector. However, refugees can lead to a fall in residential property prices if commercial real estate is a productive asset. Badarinza and Ramadorai (2018) use a "preferred habitat" framework to document that foreign risk can affect real estate valuations in global cities. We show that instability in Southern Europe was associated with bank retrenchment in Germany and impacted city-level real estate valuations in Germany.

Finally, other papers have used the government allocation of refugees for identification purposes. Dustmann, Vasiljeva and Piil Damm (forthcoming) and Eckert, Walsh and Hejlesen (2018) exploit the quasi-random nature of the refugee allocation in Denmark to study the impact of immigration on voting outcomes and the urban wage premium, respectively. We exploit the quasirandom distribution of refugees to estimate the differential impact of bank flow shocks on city business cycles. As far as we are aware, this is the first paper that uses the spatial distribution of refugees as an instrument for property prices. Moreover, we provide suggestive evidence that the new instrument that we propose can be applied to the analysis of other important common shocks, such as the transmission of the ECB's monetary policy in Germany.

\section{Data}

To conduct the empirical analysis, we assembled a new and unique data set at the annual and quarterly frequency, from 2009:Q1 to 2014:Q4. ${ }^{4}$ As a source of aggregate capital flow shocks, we focus on cross-border bank flows from the BIS Locational Statistics, or "bank flows" for brevity, which is an important share of total flows (Bruno and Shin (2014)). In particular, as we motivate in Section 3.1, we will focus on the component of bank flows predicted by the GIPS spread. In addition to official city-level statistics, the data set for the main results of the paper includes an annual proprietary panel data set on residential and commercial property price indexes at the city level from Bulwiengesa AG. To study the details of the transmission mechanism, we then merge

\footnotetext{
${ }^{4}$ Appendix Table A.1 defines all city and bank-firm-level variables that we use and describes their sources.
} 
information on bank and firm characteristics from Bundesbank supervisory data and Bureau van Dijk's Amadeus with individual bank-firm relationship data from the German credit register.

\subsection{City-Level Data}

Data on residential and commercial nominal property price indexes at the city level are proprietary from the research consultancy Bulwiengesa AG, accessed through the Bundesbank. ${ }^{5}$ To construct nominal property price indexes by city and type of property, Bulwiengesa AG uses both valuation and transaction data from building and loan associations, research institutions, realtor associations, as well as the chambers of industry and commerce. As city-level CPI indexes are not available, we construct real property price indexes by using state-level official consumer price indexes. ${ }^{6}$

Both residential and commercial indexes are at the annual frequency. Residential indexes include the price of town houses, owner-occupied apartments and single-family detached homes. Commercial indexes include information on two segments of the market, retail and office buildings. The indexes are calculated at the city level as simple averages of the individual unit prices. Thus, they can be seen as common factors for city-level property prices-see, for instance, Pesaran (2015). We focus on the 79 urban areas or cities listed in Appendix Table A.4. Bulwiengesa provides commercial real estate price data for 127 urban areas. In the German national accounts, however, some contiguous urban areas are aggregated under a single administrative district identifier. $^{7}$ In our analysis, we focus on the 79 cities or areas whose geographical definition is the same as in the national accounts, so as to match data from the two sources exactly.

In order to construct our instrumental variables described in more detail in Section 3.2 and to conduct various robustness exercises, we merge data on refugees, population levels and population density from the German Federal Statistical Office with land use data from the German Monitor of Settlement and Open Space Development (IOER Monitor), which is a detailed database that combines information from satellite imaging with geo expert data and other statistical sources,

\footnotetext{
${ }^{5}$ The Bundesbank relies on this provider for the publication of national indexes, also shared with the European Central Bank.

${ }^{6}$ Germany is a diversified large economy and inflation was low and stable during the period we consider. Hence, it should not make a difference whether we use city-level or state-level CPI deflators.

${ }^{7}$ For instance, the city of Hanover and its hinterland were merged into one larger administrative district in 2001, which includes the city of Hanover itself and 20 other smaller municipalities.
} 
capturing both man-made and geographical limits on real estate supply.

The dependent variable in our main city-level regressions is real per capita GDP growth. As city-level GDP deflators are not available, we construct real GDP by using the same official statelevel consumer price indexes used to deflate property price indexes. We match real GDP and real estate price data with a number of other city-level variables. The matching of all city-level data is straightforward because it is based on a common city identifier across all variables. Both real GDP per capita growth and the share of refugees are winsorized at the $1 \%$ and $99 \%$ levels. Winsorizing all other series at the this level does not affect the results of the empirical analysis.

\subsection{Bank-Firm-Level Data}

To explore the relationship among capital flows, bank lending, firm decisions and commercial property prices, we match data from the German credit register over the period 2009:Q1-2014:Q4 with Bundesbank bank balance sheet data and firm-level data from Bureau van Dijk's Amadeus.

The German credit register contains information on bank exposure, including loans, bonds, off-balance sheet, and derivative positions (excluding trading book positions). ${ }^{8}$ Financial institutions in Germany are required to report to the credit register if their exposure to an individual borrower, or the sum of the exposures to borrowers belonging to one legal entity, exceeds a threshold of 1 million euro. A legal borrowing entity comprises independent borrowers that are legally or economically connected to each other due to majority ownership (more than 50\%), or due to profit transfer agreements. Consequently, the effective reporting threshold is usually lower than 1 million euro. ${ }^{9}$ A borrowing entity in the credit register, however, can have multiple bank relationships. The German credit register captures about two-thirds of bank credit outstanding. That is, if we sum all loans reported in the credit register in a given quarter, this amounts to about two-thirds of total credit outstanding as reported by German official bank balance sheet statistics.

We match credit register data with information on bank balance sheets from Bundesbank su-

\footnotetext{
${ }^{8}$ For a more detailed definition of bank exposure, see Section 14 of the German Banking Act: https://www.bundesbank.de/Redaktion/EN/Downloads/Tasks/Banking_supervision/Acts_Regulations_ Guidelines/banking_act.pdf?_blob=publicationFile.

${ }^{9}$ The official reporting threshold was lowered from 1.5 million to 1 million euro in 2014 . Due to the relatively low effective reporting threshold, however, this reduction does not affect our results.
} 
pervisory data. ${ }^{10}$ Balance sheet data include total assets, liquid assets, the interbank-to-deposit funding ratio, the regulatory-capital ratio, non-performing loans, the return on assets and net and gross bank foreign assets. We also match firm-level accounting variables from the Bureau van Dijk's Amadeus with the credit register data. In our analysis, we use firms' total assets (defined as the sum of current assets and non-current assets), tangible fixed assets (i.e., property, plant and equipment-PPE), total fixed assets, the equity-to-asset ratio, the return on assets, the number of employees and capital expenditures.

Our proxy for real estate collateral at the firm level, or collateral for brevity, which plays a critical role in the second part of our empirical analysis, is the share of tangible fixed assets in total assets. Unfortunately, the German credit registry does not include information on collateral. In addition, Amadeus data do not provide separate information on buildings, land and improvements, and construction in progress, the three categories of tangible fixed assets that are usually considered corporate real estate assets in accounting definitions. However, for the United States, real estate is estimated to be a sizable fraction of total fixed assets, total assets, and firms' market values for publicly listed companies-see, for instance, Chaney et al. (2012) and Nelson, Potter and Wilde (2000)). Real estate assets are usually assumed to be even more important for private firms. Moreover, Laposa and Charlton (2002) estimate that European corporate holdings of real estate assets of publicly listed companies are even higher (as a share of total assets) than in the United States due to the underdevelopment of the property management industry. For example, recent estimates of the share of real estate assets in total assets for German public companies, up to 2013, show substantial variation across sectors and, unlike the United States, limited decline over time during the sample period we study (Rochdi (2015)). As we argue in the paper, while the proxy variable that we use is an imperfect measure of firm-level real estate collateral, one clear advantage of using total fixed tangible assets from Amadeus is that this indicator is available not only for publicly listed companies, but also for smaller and private firms.

The data matching at the bank-firm level is challenging because the German credit register and the Amadeus database do not share a common identifier. We proceed as follows. First, we match by the unique commercial register number, when it is available. Second, for observations without

\footnotetext{
${ }^{10} \mathrm{We}$ match the end-quarter values of these variables to the credit register data.
} 
this identifier, we rely on Stata's reclink command. ${ }^{11}$ At this step, we match firms either by their name and zip code or by their name and city, with a minimum matching reliability of 0.99 . We then match the remaining firms manually. ${ }^{12}$ Overall, we can track the records of more than $44 \%$ of German firms included in the credit register during the sample period, slightly more than in previous studies using these data (see for instance Behn, Haselmann and Wachtel (2016)). ${ }^{13}$

In order to focus on commercial banks, we exclude investment funds and special purpose vehicles that are less likely to be extend traditional loans. The resulting sample after this adjustment comprises approximately 700,000 bank-firm-quarter observations, including multiple firm-bank relationships. Appendix Table A.2 reports summary statistics for all variables used in the analysis.

\section{Empirical Strategy}

Capital flows can affect the economy through multiple channels. Capital flow shocks can loosen domestic financial conditions and increase credit supply. Increased credit supply can stimulate real estate markets and property prices. Higher property prices can amplify the initial credit impulse through collateral channels on the household or the firm side, driving investment, employment, and other firm outcomes. ${ }^{14}$

Figure 3 summarizes some of the channels through which capital flows can affect city activity at the business cycle frequency. The solid arrows represent causal linkages and the dashed arrows reverse causal effects. The top arrows represent the traditional push-pull view of the short-run association between capital flows and cyclical indicators of economic activity. The inner loop emphasizes the role of credit in this transmission, and its two-way connection with property prices, which has been extensively studied in the literature. The outer loop represents the possible role of

\footnotetext{
${ }^{11}$ See RECLINK: Stata module to probabilistically match records available.

${ }^{12}$ We matched 4,143 firms in the first step, 23,010 firms in the second step, and 1,038 firms by hand and hence more than 28,000 in total.

${ }^{13}$ Table A.3 provides a summary statistics comparison between matched and not matched firms. Matched firms are larger, have higher shares of tangible assets, lower equity ratios and returns on assets, possibly indicating that firms in our sample are older and more mature.

${ }^{14}$ Among others, see Mian et al. (2017)), Hoffmann and Stewen (forthcoming), Baskaya, Giovanni, Kalemli-Ozcan and Ulu (2018) on capital flows and credit supply; see Favara and Imbs (2015), Di Maggio and Kermani (2017) on credit and property prices; see Iacoviello (2005) and Liu et al. (2013) for general equilibrium models of amplification via real estate collateral and prices on the household or the firm side, respectively; see Chaney et al. (2012), Gan (2007), Cvijanović (2014) and Adelino et al. (2015) on property price, collateral, and firm outcomes.
} 
Figure 3 TRANSMISSION MECHANISM: ROAD-MAP

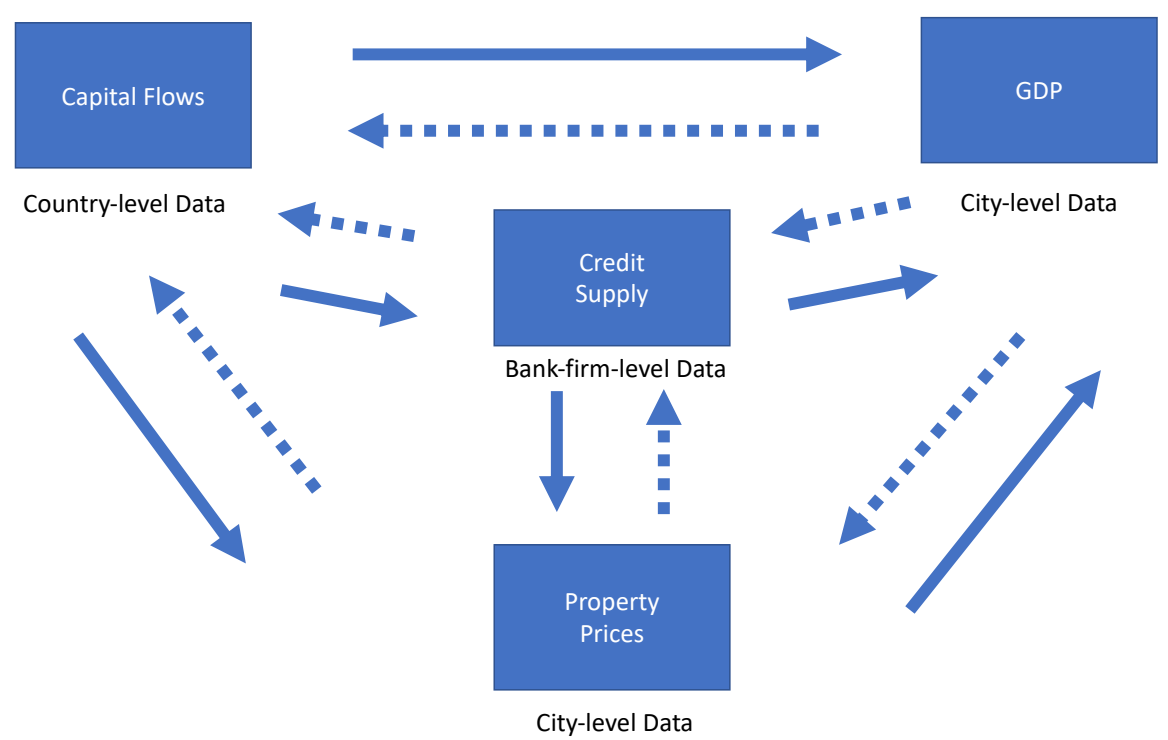

real estate markets in the transmission of capital flow shocks that we want to explore in this paper.

The central hypothesis of our empirical analysis is that the tighter a city's real estate markets are, the more significant is the impact of bank flow shocks on the city's output growth. In a given local real estate market, all else equal, a tighter real estate market due to an exogenously lower net supply of real estate should translate into a higher sensitivity of property prices to housing demand and supply shocks. Cities with tighter real estate markets, therefore, should be more sensitive to capital flow shocks than other cities, assuming that the transmission mechanism sketched out above is at work. Moreover, consistent with macroeconomic models with borrowing constraints as in Kiyotaki and Moore (1997) in which real estate serves as collateral, as well as our simple model in the Appendix and abundant macroeconomic evidence that capital inflows are correlated with outcomes in housing markets and real GDP growth, our prior is that property price increases should play an important role in the transmission of bank flow shocks to output growth.

The econometric challenge to investigate the outer loop in Figure 3 by exploiting local variation in the data, therefore, is to propose a measure of exposure to pressure or tightness in real estate markets that varies quasi-randomly across cities. Equipped with such an exogenous city- 
level measure of exposure, we can then use the predicted component of property price changes triggered by an aggregate capital flow shock to estimate the impact on city output growth. Taken together, these two steps can provide an estimate of the causal effects of capital flow shocks on city output growth through property price changes. Thus, the identification strategy in the first part of the analysis, based on city-level data, is one of identification by geographic variation. The research design is grounded on (i) the availability of a well-defined aggregate or nation-wide measure of capital flows and (ii) the construction of an indicator of real estate market tightness (or exposure) that varies randomly across cities, which we discuss in more details below.

Even though the inner loop in Figure 3 is not our main focus, in the second part of the paper, we want to open up the black box of the transmission mechanism possibly underlying our reduced form instrumental variable estimates. In particular, we will provide evidence on the role of real estate collateral in the allocation of the increased credit supply triggered by the capital flow shock, as on the left-hand side of the inner loop of Figure 3. Finally, we will also focus on firm employment and investment decisions and total factor productivity at the firm and industry level, as well as capital misallocation, as on the right-hand side of the inner loop of Figure 3. The empirical strategy to address endogeneity concerns, here, will rely on the availability of matched bank-firm level data combined with suitable regression designs typically used in the empirical banking literature and the literature on firm behavior. ${ }^{15}$

\subsection{Measuring Capital Flows: Cross-border Bank Flows and the GIPS Spread}

As measured by the current account surplus of the balance of payments, Germany experienced sizable net capital outflows rather than inflows throughout the period we consider (Figure 4, Panel A). The current account balance, therefore, is not a suitable measure for our empirical analysis. From this figure, however, we can also see that the current account surplus vis-a-vis the rest of the euro area started to decline during the GFC, and continued in that direction throughout the period we consider. In contrast, the current account surplus vis-a-vis the rest of the world outside the euro area became even larger after 2009:Q1. Moreover, Panel B of Figure 4 shows that the net foreign

\footnotetext{
${ }^{15}$ To conserve space, the paper does not report evidence on the impact of increased credit supply triggered by the capital flow shock that we identify, but unreported regressions show that it is consistent with the collateral channel we emphasize.
} 
asset position of German BIS reporting banks changed dramatically during and after the GFC. In the rest of the paper, therefore, we will focus on cross-border bank flows, labeled "bank flows" for brevity, which are an important component of total flows.

Figure 4 Current Account Balance And Net Bank Flows

Panel A: Current Account Balances (\% of GDP)

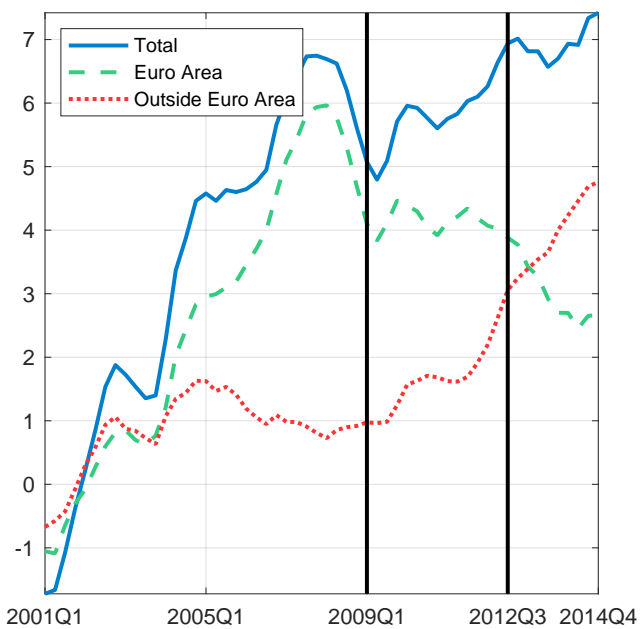

Panel B: Net Bank Inflows (\% of GDP)

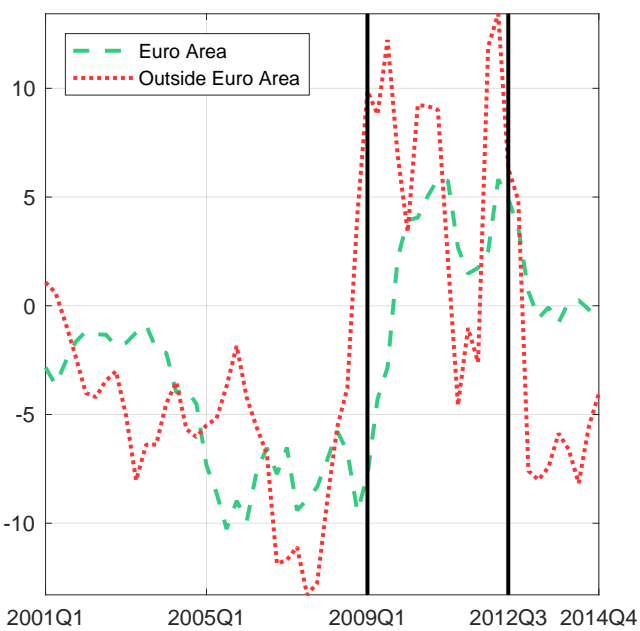

NotE. Panel A plots the current account balance as a share of GDP, together with its breakdown vs. the rest of the euro area and outside the euro area. Panel B plots net bank flows vs. the rest of the euro area and vs. outside the euro based on BIS Locational Statistics. The vertical bars mark the beginning of the post-GFC recovery in 2009:Q1 and the "Whatever It Takes" speech by ECB Governor Draghi in 2012:Q3, respectively. See the Data Appendix for variable definitions and data sources.

Aggregate cross-border bank flow data pose their own challenges because subject to measurement errors and contaminated by foreign currency valuation effects difficult to account for. Moreover, our sample period is rather short from a time series perspective. An alternative measurement approach, often employed in the extant literature, is to use price-based indicators that comove closely with quantity-based measures of bank flows. One indicator often employed to capture bank flows driven by global risk or risk aversion is the US VIX index of implied equity market volatility (e.g., Forbes and Warnock (2012)). Following this approach and consistent with theoretical models of retrenchment transmission (Caballero and Simsek (forthcoming)), as a proxy for bank flows, we use an indicator of financial instability and risk in Southern Europe, namely the average sovereign bond spread of Portugal, Italy, Greece, and Spain vs. Germany, henceforth 


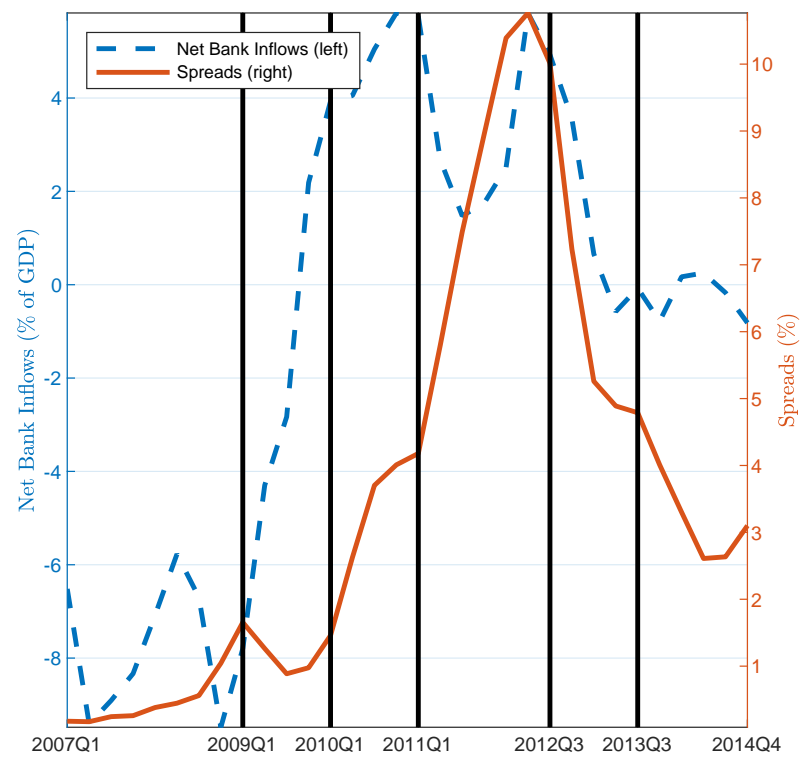

Note. The figure plots the GIPS spreads and Net Bank Inflows (\% of GDP). The five vertical lines mark the following events: (1) the beginning of the German recovery in 2009:Q1; (2) Greek bonds downgraded to junk status and the Troika's launch of the 2010 110-billion euro bail-out; (3) 2011 downgrade and euro area leaders' disagreement on the rescue package for Greece; (4) "Whatever It Takes" speech by ECB Governor Draghi; and (5) interest rate cuts by the ECB. See the Data Appendix for variable definitions and data sources.

called the GIPS spread. The GIPS spread is plotted in Figure 5, together with German bank flows vs. the rest of the euro area from Panel B of Figure 4. From this figure, we can see that the turning points in the GIPS spread correlate closely with net bank flows vs. the rest of the euro area and are also closely associated with the development of the sovereign debt and banking crisis in Southern Europe.

To quantify more precisely the relevance of the GIPS spread as predictor of bank flows, as the first step in our empirical analysis, we run a battery of regressions for alternative bank flow measures on the GIPS spread. The frequency is quarterly and the sample period is 2000:Q1-2014:Q4 to make sure that the spread can capture both phases of the boom-bust cycle. The estimated equa- 
tion is specified as follows:

$$
\mathrm{BF}_{t}=\gamma \cdot \operatorname{Spread}_{t}+\varepsilon_{t}
$$

where $\mathrm{BF}_{t}$ represents alternative measures of bank flows, and "Spread $t$ " denotes the GIPS spread. We distinguish between net flows from outside and inside the euro area. We then break down net flows from the rest of the euro area into gross inflows and outflows. Following Larrain and Stumpner (2017), we also examine the impact of the GIPS spread on the domestic lending-deposit interest rate spread. If bank flows increase domestic credit supply, we should observe a negative effect on the domestic lending-deposit spread. Finally, we use our bank-level data to evaluate the predictive ability of the GIPS spread for individual banks' gross foreign assets as a share of total assets, controlling for bank fixed effects. The last regression is important as concerns regarding reverse causation from bank flows to the GIPS spread are mitigated by the use of bank-level data.

Table 1 THE GIPS SPREAD AND BANK FLOWS

\begin{tabular}{|c|c|c|c|c|c|c|}
\hline & Country-Level & Country-Level & Country-Level & Country-Level & Country-Level & Bank-Level \\
\hline & (1) & (2) & (3) & (4) & (5) & $(6)$ \\
\hline & Net Bank Inflows & Net Bank Inflows & Gross Bank Inflows & Gross Bank Outflows & Lending-Deposit & Bank Share of Gross \\
\hline & Outside Eurozone & Inside Eurozone & Inside Eurozone & Inside Eurozone & Spread & Foreign Assets \\
\hline \multirow[t]{2}{*}{ GIPS Spread $_{t}$} & 0.790 & $0.991^{* * *}$ & -0.160 & $-1.151^{* * *}$ & $-0.115^{* * *}$ & $-0.246^{* * *}$ \\
\hline & $(0.855)$ & $(0.223)$ & $(0.209)$ & $(0.261)$ & $(0.026)$ & $(0.030)$ \\
\hline Bank FE & - & - & - & - & - & Yes \\
\hline Obs & 60 & 60 & 60 & 60 & 48 & 89,651 \\
\hline$R^{2}$ & 0.033 & 0.216 & 0.009 & 0.238 & 0.247 & 0.844 \\
\hline
\end{tabular}

NoTE. All regressions are based on quarterly data over the period 2000:Q1-2014:Q4, except for the regression in Column (5) for which the data are not available before 2003. The dependent variable in Columns (1) and (2) is net bank flows into the German banking system from the rest of the world outside the euro area and from the rest of the euro area, respectively. In Columns (3) and (4), the dependent variable is gross inflows and outflows from the rest of the euro area, respectively. In Column (5), the dependent variable is the difference between the domestic lending and deposit interest rate. In Column (6), the dependent variable is the share of individual banks' gross foreign assets over total assets. The regression in Column (6) includes individual bank fixed effects. See the Data Appendixes for variable definitions and data sources. Heteroskedasticity-robust standard errors are shown in parentheses. ${ }^{*},{ }^{* *}$ and ${ }^{* * *}$ indicate statistical significance at the $10 \%, 5 \%$, and $1 \%$ level, respectively.

Table 1 reports the results. Columns (1) and (2) show that a higher GIPS spread is positively associated with net bank flows into Germany from both outside and inside the euro area. The relation, however, is statistically significant only for net bank flows originating from the rest of the euro area. The results in Columns (3) and (4) also illustrate that net bank flows are driven by lower gross bank outflows, rather than higher gross bank inflows. These regressions, therefore, taken 
together, suggest that a GIPS spread increase is associated with a repatriation of bank foreign assets from the rest of the euro area, which Forbes and Warnock (2012) call "retrenchment" of capital.

The evidence of retrenchment is further corroborated by Column (6), which shows that a higher GIPS spread is associated with a smaller share of gross foreign assets in total bank assets at the level of individual banks. This last regression suggests that, in economic terms, a 100-basis points increase in the GIPS spread reduces banks' share of foreign assets in total assets by almost 25 basis points. Put it differently, this estimate implies that, during the peak of the European crisis, the German banking system shifted lending from foreign to domestic borrowers amounting to about $1.6 \%$ of its aggregate balance sheet, or $1.9 \%$ of GDP. ${ }^{16}$

As shown in Column (5), a higher GIPS spread is also associated with a lower domestic lending-deposit spread, suggesting that the German bank retrenchment episode we consider is associated with looser domestic financial conditions and an aggregate increased supply of credit. Moreover, as we will report and discuss in Section 6, a higher GIPS spread leads to lower debt service costs at the firm level. This transmission, therefore, is in line with the hypothesis that a bank flow shock can loosen domestic financial conditions and increase the domestic credit supply.

Appendix Table B.1 shows that these results are similar if we restrict the sample to the 20072014. The same table shows that the important result in Column (6) of Table 1 is robust to adding a comprehensive set of macroeconomic and bank-level control variables. In unreported regressions, we also obtain essentially the same results as in Column (6) above by using net, rather than gross, individual bank foreign assets. ${ }^{17}$ Finally, the results are also unchanged if we include in the construction of the GIPS spread Ireland, or exclude Greece, as the sovereign bond spreads are highly correlated in crisis times.

In summary, this evidence documents that German banks experienced a sizable net inflow of capital from the rest of the Euro Area since the GFC, driven by German banks' repatriation of foreign assets, consistent with available evidence on the behavior of Northern European banks

\footnotetext{
${ }^{16}$ The GIPS spread averaged 6.5\% during the acute phase of the European crisis, from 2010:Q1 to 2012:Q3, compared to a value close to zero right before the GFC. Hence, the impact of the crisis is quantified as $6.5 \% * 0.246=1.60 \%$. According to FRED data, total assets held by deposit money banks compared to GDP were approximately $120 \%$ in 2009. As a result, the estimated shift in banking assets is $1.60 \% * 1.2=1.92 \%$ of GDP.

${ }^{17}$ All results not reported in the paper are available from the authors on request.
} 
before and after the GFC discussed in Section 1. The evidence also shows that the GIPS spread is a good predictor of bank flows. Based on these preliminary findings, in the rest of the paper, we will use the GIPS spread as a our proxy for bank flows.

\subsection{Identification: Refugees and Real Estate Markets Tightness}

The main goal of the paper is to identify the output growth impact of property price variation across cities triggered by an aggregate change in bank flows. For this purpose, we construct a measure of city exposure to real estate market tightness that varies quasi-randomly across cities. Our exposure measure exploits features of a long-standing German policy framework for the allocation of refugees across cities that makes their distribution quasi-random. As we describe in more details below, and as is also illustrated in a simple model of local real estate markets developed in the Appendix, refugees tighten the local net supply of commercial and residential real estate services because one of their basic needs is shelter. In addition to the city distribution of refugees, we also utilize a traditional indicator of real estate supply scarcity in the spirit of Saiz (2010) that controls for the city variation in geography and land-use regulations. Thus, our exposure measure is the product of the share of refugees in total refugees and a measure of non-developable area. Even though our exposure measure has little time variation, we hold it constant at the pre-sample value of 2008 to isolate the time-varying effect of the bank flow shock. We now discuss each of these two components of our exposure measures in more detail. ${ }^{18}$

\subsubsection{The City Allocation of Refugees: Institutional Details and Economic Rationale}

The first component of our exposure measure is the share of refugees allocated by government policy to a given city relative to the total number of refugees in the country in 2008 , which we call the share of refugees. ${ }^{19}$ The share of refugees is a good candidate instrument since it is distributed quasi-random with respect to local business cycle conditions. This is because, in Ger-

\footnotetext{
${ }^{18}$ The 2008 value of the share of refugees, the non-developable area indicator, and their product for all 79 cities is reported in Appendix Table A.4.

${ }^{19}$ In international treaties, "asylum seekers" are individuals applying for asylum, and "refugees" refers to individuals whose asylum status has been approved and are entitled to the associated benefits, including housing benefits. In the German statistics, the total number of refugees includes (i) admitted refugees on a permanent basis, (ii) admitted refugees on a temporary basis, (iii) rejected asylum seekers that cannot be relocated, and (iv) a small fraction of asylum seekers not processed within the year.
} 
many, refugees are allocated across states and cities according to federal laws and regulations governing asylum seeking, the granting of refugee status and their benefit entitlements, including housing. Unlike other categories of migrants, therefore, refugees cannot settle freely across cities in Germany. ${ }^{20}$ As the share of refugees is a new instrument, it is useful to discuss critical details of the German institutional framework and the economic rationale for its relevance, in both the commercial and the residential sectors. ${ }^{21}$

Table 2 Within-State Refugee Allocation Criteria And Housing Solutions

\begin{tabular}{lcc}
\hline \hline State & Allocation Criteria & $\begin{array}{c}\text { Refugees in Independent } \\
\text { Accommodations }\end{array}$ \\
\hline Baden-Württemberg & Population & 35.0 \\
Bavaria & Population & 32.0 \\
Berlin* & NA & 17.0 \\
Brandenburg & Population, number of employees & 30.0 \\
Bremen* & NA & 60.0 \\
Hamburg* & NA & 25.0 \\
Hesse & Population & 50.0 \\
Lower Saxony & Population & 67.0 \\
Mecklenburg-Vorpommern & Population & 71.0 \\
North Rhine-Westphalia & Population, total area & 63.0 \\
Rhineland-Palatinate & Population & 78.0 \\
Saarland & Population & 79.0 \\
Saxony & Population & 53.0 \\
Saxony-Anhalt & Population & 72.0 \\
Schleswig-Holstein & Population & 62.0 \\
Thuringia & Population level in 1998 & 57.0 \\
\hline
\end{tabular}

Note. The table describes the refugee allocation criteria across cites within all 16 German states, based on Müller (2013). The table also shows the share of refugees housed in independent accommodations, such as apartments and single-family homes, as opposed to accommodation centers and other publicly-run facilities using commercial real estate space, based on data provided by Baier and Siegert (2018). Note that Berlin, Bremen and Hamburg are citystates, denoted with a $*$, and therefore do not have independent within-state allocation criteria.

The well-known federal Koenigsteiner Schluessel (KS) rule determines annually quotas for the distribution of refugees across German states based on state population in total population (with a weight of 1/3) and the percent of state tax revenue in total tax revenue over the previous two years (with a weight 2/3). Because of the dependency of the KS rule on past tax revenue, the state allocation of refugees could be endogenous to business cycle conditions. Nonetheless, we can see from Table 2, which summarizes the criteria for the city allocation within each state,

\footnotetext{
${ }^{20}$ Similar allocation rules apply in other Northern European countries such as Norway and Denmark. See, for instance, Eckert et al. (2018) and Dustmann et al. (forthcoming).

${ }^{21}$ The main sources of information on the institutional details of German refugee policy on which we relied upon are Müller (2013), Baier and Siegert (2018) and Nam and Steinhoff (2018).
} 
that the rules governing the city allocation of refugees within states do not depend on tax revenue. Individual states have similar, but not identical allocation systems across cities. Although there is some heterogeneity, most states determine the city-allocation of refugees based only on population shares, while some also use surface or area, neither of which depends on growth outcomes at business cycle frequency. In particular, no state uses lagged tax revenue, although Brandenburg employs the number of employees as secondary criterion. Moreover, cities have no influence on the characteristics of the allocated refugees, such as the country of origin, skills and education, or other background. Finally, the predictability and efficiency of this system is well-known with small deviations from the assigned quota. Indeed the correlation between the city share of refugees in 2008 and the population share is close to $1 .^{22}$

Refugees assigned to a given city cannot easily relocate in Germany. Upon arrival, asylum seekers must apply for status at the assigned federal office for immigration and refugees (BAMF). After registration, medical assessment, and submission of asylum applications in these centers, the refugees are distributed to the municipalities within the state according to the quota systems in Table 2. A first-round decision on status is supposed to be taken within six months. While an application is pending, asylum seekers are required to stay at the initial accommodation center and cannot leave the area without permission. Only if and when BAMF grants status, refugees can relocate. However, even after asylum is granted, if a refugee is not financially self-sufficient, the government continues to determine where subsidized shelter is provided. As many applications are initially rejected, and most asylum seekers appeal in the courts, which typically takes a year or more, refugees usually remain confined to their initial city assignment for much longer than the minimum time necessary to obtain status.

In Germany, refugees are also unlikely to have any impact on the labor market at business cycle frequency, even after they reach status. The main reason is a legal requirement of working knowledge of the German language for formal employment in most occupations that was in place until changes were introduced in 2015 and 2016. The law also entailed preferences toward German

\footnotetext{
${ }^{22}$ Note here that Berlin, Bremen and Hamburg are city-states and do not have independent within-state allocation criteria. Berlin and Hamburg are also among the largest German cities and have the highest share of refugees-see Appendix Table A.4. Because of the potential endogeneity of the refugee allocation to economic activity, we will drop the city states from the sample in our empirical analysis. Indeed, in unreported regressions, we find that including city-states would bias downward our estimates.
} 
and European applicants, as well as other restrictions on permits for refugees who did not complete vocational training. ${ }^{23}$ For example, Mayda, Parsons, Pham and Vezina (2019) estimate that the rate of employment of refugees is less than $14 \%$ within two years after they receive their work permit. Moreover, most of these jobs, are temporary and low-skill according to OECD (2016). Indeed, unreported results of unemployment data show that, in our data, there is no association between city unemployment rates and our exposure measure or its components.

As we illustrate with a simple model of local commercial and residential property markets reported in Appendix, the key reason why the city share of refugees can be a relevant instrument in the commercial sector is that refugee reception centers compete for built-up structures and developable land with other uses, such as Accommodation, Health Care, Transportation and Warehousing. Indeed, in Germany, the government provides both short-term shelter in accommodation centers for asylum seekers and long-term affordable housing solutions for refugees who cannot self-sustain financially, ultimately putting pressure on the net supply of both commercial and residential real estate services that is inelastic in the short term. For instance, anecdotal evidence suggests that cities initially use up hotel capacity, school gymnasiums, retirement homes and other facilities devoted to social housing and idle spaces before being able to expand the affordable housing supply, which requires approval, design and construction. Once asylum seekers reach status, refugees who cannot self-sustain continue to be housed in collective living facilities or they are granted the right to independent accommodation depending on the public interest and individual circumstances. The decision is at the discretion of the local government. As we can see from Table 2, however, most refugees end up accommodated in collective facilities, with a minimum of $20 \%$ and peaks of $70 \%$ of the total housed this way, even excluding the city states of Berlin and Hamburg that provide independent accommodations toonly 17 and $25 \%$ of their refugees, respectively.

In Germany, there are institutional reasons to presume that the city share of refugees could also be a relevant instrument for property prices in the residential sector. One is that, as the

\footnotetext{
${ }^{23}$ Refugees are not allowed to work during the first 3 months after arrival. Between month 4 and 15 , they are allowed to work only if the Federal Employment Agency agrees that no other German is equally suitable for the same position and that the wage offered is comparable to the market rate. Between month 16 and the end of the third year, they are allowed to work only if their wage is deemed market comparable. Starting with the 4th year, they can work without restrictions.
} 
existing allocation rules do not take into account population density, or other characteristics of the receiving cities linked to land use or scarcity, they put disproportionate pressure on cities already facing excess demand for social housing. ${ }^{24}$ However, this is particularly the case for the three German city-states excluded from our sample rather than the 13 states that are included. Another is that local governments try to avoid creating segregated enclaves, as this can be counterproductive for long-term integration prospects of refugees. Yet, local residents of affected neighborhoods can respond with relocation, bringing pressures to higher segments of the residential real estate markets-see Tumen (2016) for evidence of this segregation effect of Syrian refugee inflows on residential house prices in Turkey.

Nonetheless, as our model in the Appendix shows, the impact of a higher share of refugees on residential property prices is theoretically ambiguous. In the data, we also find that our exposure measure is not a good predictor of residential property prices, consistent with neighborhood-level evidence from the German city of Hamburg in Dehos and Eilers (2018). In fact, our model shows that, if commercial real estate services are a factor of production, a higher share of refugees has an unambiguous positive impact on commercial property prices, but not on residential prices. This is because a higher share of refugees reduces the net supply of real estate services for other uses in both sectors. A lower net supply of commercial services, translates directly into higher property prices in the commercial sector, but also lower output and income. Moreover, the fiscal transfer needed to finance refugee benefits might further affect disposable income of residents. As a result, refugees also put direct upward pressure on residential property prices, but with lower output and a higher fiscal transfer from residents to pay for their welfare, local disposable income falls and the consumption of housing services of the city residents falls with a countervailing effect on residential prices. The net effect of these two forces depends on parameter values. Indeed, when we calibrate our model to capture the institutional details of the German policy framework (without city states) and salient features of our city-level data base, we find that, with a higher share of refugees, residential property prices fall rather than increase-see Appendix Figure C.1. In contrast, an alternative calibration that would better characterize the three city states excluded

\footnotetext{
${ }^{24}$ For example, one of the changes to the system that the German parliament contemplated during the Syrian refugee crisis is the introduction of population density criteria in the allocation rules to contain the perceived strong impact on the local real estate markets.
} 
from our sample delivers higher residential prices in cities with a higher share of refugees.

In light of this, in order to rule out drawing conclusions on the role of the residential sector based on a possibly weak instrument, in our empirical analysis, we will also use an alternative instrument for residential property prices. The alternative instrument for the residential sector will be the city share of population in the $25-30$ age bracket, called the city share of young people in 2008. The share of young people is a plausible alternative instrument because its city distribution is relatively stable over time and unlikely to respond to short-to-medium term business cycle conditions. ${ }^{25}$ This variable is also a potentially relevant instrument because younger people are more likely to rent. Higher rents, in turn, can attract buy-to-let domestic and (deep-pocket) foreign investors that might have played an important role in igniting the German residential housing boom. $^{26}$

\subsubsection{Natural and Man-made Supply Constraints}

The second component of our exposure measure is the ratio of non-developable land to the total built-up area, including residential and commercial structures and buildings in 2008, which we call non-developable area ratio or land share for brevity, and define precisely in Table A.4. Based on our granular IOER Monitor data, one can easily construct variants of the non-developable area measure that we use. One could use shares relative to the total area, or consider other land use partitions, for instance including areas destined to transportation and/or forestry in the definition of non-developable area which are excluded from our definition actually employed in the empirical analysis. One could also construct a sector-specific indicator for the commercial and the residential sectors. As additional non-reported evidence can show, the advantage of the specific indicator that we use is that it performs well in both East and West German cities, with economically plausible unconditional correlations with the average property price growth in both real estate sectors, simplifying the formulation of the econometric model that we use and the presentation of

\footnotetext{
${ }^{25}$ The correlation between the share of young people and its own lag is $98 \%$. For example, the city with the lowest share of people in this age bracket in our sample is Suhl in East Germany, with a 2008 value of 5.1\%. In 2014, this city had a share $5.2 \%$ share. The city with the highest proportion of young people is Wuerzburg in West Germany, with a values of $10.3 \%$ in 2008 and $11.1 \%$ in 2014.

${ }^{26}$ This hypothesis is consistent with the decline (increase) of a full percentage point in the German home ownership (tenancy) rate over our sample period that is reported by the Eurostat and the German Federal Statistical office data. See also work in progress by Blanc, Kindermann, Piazzesi and Schneider (2020).
} 
our main results.

The rationale for interacting the share of refugees with a non-developable area indicator is that a marginal change in the city share of refugees will have a different impact on property prices in cities in which supply constraints due to land-use regulations and geography are tighter. Our theoretical model in the Appendix assumes that the supply of real estate services is completely fixed in both sectors, and city variations in real estate supply translate in different sensitivities of property prices to the city share of refugees.

However, unlike in the United States or other European countries like Italy or Switzerland, in Germany, city variation in the incidence of steep-slope terrains and water bodies has a much more limited impact on the distribution of non-developable area across cities (OECD (2017)), especially in East Germany. Furthermore, in Germany, land-use regulations are distributed more uniformly than in the United States — see, for instance, Schmidt and Buehler (2007). This is why using only a measure of housing supply elasticity in the spirit of Saiz (2010) would not yield a relevant instrument. ${ }^{27}$ For both theoretical and institutional reasons, therefore, it is useful to interact a traditional Saiz (2010)-type of instrument with our share of refugees.

In sum, the institutional details of the German policy framework for the allocation of refugees across cities and the preliminary and auxiliary evidence discussed suggest that our measure of exposure to real estate market tightness, as well as our alternative indicator for the residential sector, are good candidate instrumental variables for our empirical analysis. The orthogonality condition for the validity of these instruments cannot be established formally, while econometric evidence on the relevance condition will be presented with the first stage regressions of the econometric specifications that we use in the next section. So we can now move to the presentation of the main empirical results of the paper. In the next section, therefore, we will use these two variables interacted with the GIPS spread to investigate the role of real estate markets, and property price changes more specifically, in the transmission of bank flow shocks to city output growth as captured by the GIPS spread.

\footnotetext{
${ }^{27}$ Indeed, in unreported preliminary analyses of the data, we find that the supply elasticity indicator that we use would be a relevant instrument only in the residential sector of West German cities, consistent with the widespread application of the Saiz (2010) measure in the United States, but not in the commercial sector or the residential sector of East Germany.
} 


\section{Bank Flows, Real Estate Markets, and City Business Cycles}

The hypothesis in the paper is that higher property prices, triggered by aggregate capital flow shocks, may have a stronger impact on output growth in cities with tighter real estate markets. In this section, we investigate this hypothesis empirically, for both the residential and the commercial sectors, exploiting the quasi-random city variation in our measure of real estate market tightness or exposure to achieve identification. Our main "instrument" is the interaction of the aggregate bank flow, as captured by the GIPS spread, with the city-level measure of exposure in 2008. While the GIPS spread is likely endogenous to economic conditions in individual German cities in which banking activity is concentrated, its interaction with the exposure measure, whose city distribution is assumed to be unrelated to local and aggregate economic conditions, provides an exogenous source of variation in the bank flow shock intensity that can be related to city differences in economic performance.

\subsection{Reduced Form Estimates}

Equipped with a proxy for bank flows and a measure of city exposure to real estate market tightness, we start by estimating the following simple city-level reduced form regression:

$$
\Delta G D P_{c, t}=\alpha_{c}+\alpha_{t}+\beta \cdot\left(\operatorname{Spread}_{t-1} \times \text { Exposure }_{c, 2008}\right)+\varepsilon_{c, t}
$$

where $G D P_{c, t}$ is $\log$ real GDP per capita in city $c$ at time $t, \operatorname{Spread}_{t-1}$ is our proxy for bank inflows at time $t-1$, and Exposure $e_{c, 2008}$ is the value of our exposure measure to local real estate market tightness in 2008. The latter is assumed to be uncorrelated with the error term, $\varepsilon_{c, t}$. Even though bank inflows, and hence the GIPS spread, might be endogenous to business conditions in some German cities, once interacted with our exposure measure, the differential impact of the GIPS spread across cities, as measured by the $\beta$ regression coefficient in equation (2), is well identified. Hence, this regression quantifies the extent to which a city's sensitivity to the aggregate state of the GIPS spread varies based on the degree of local real estate market tightness.

Table 3 displays the empirical results. As a benchmark, Column (1) reports an estimate of the 
interaction effect, measured by the coefficient of interest $\beta$, which can be interpreted as a causal impact under our identification assumptions, without time or city fixed effects. The regression in Column (2) is saturated with city and time fixed effects to control for the direct influence of city-specific factors and common shocks, such as city size and common factors across cites in the German business cycle. City size is particularly important because larger cities tend to grow disproportionately more due to agglomeration forces. In addition to fixed effects, Columns (3)-(6) control for the interactions between other common factors that might transmit through the local real estate markets and our exposure measure. With these latter specifications we ensure that the GIPS spread does not capture the impact on city output growth of the ECB's monetary policy response to the European crisis or the drop in the German Bund term premium that we saw in Panel B of Figure 1, which also drive the fall in German mortgage rates (not reported) during the sample period. This is important because these confounding shocks also hitting German cities during the 2009-2014 period are likely to be correlated with the capital flow shock and could affect German cities differently depending on the exposure to real estate market tightness. ${ }^{28}$ Finally, Columns (7) and (8) add to the specification in Column (3) the interaction of the GIPS spread with the city-level share of population or population density. These last two specifications rule out that the exposure measure identifies differences between large and small cities or congested and non-congested cities, rather than real estate market pressure as intended. Columns (7) and (8), therefore, are the most conservative specifications, as we do not only include one demographic factor at the time, but also control for the concomitant presence of all other common shocks considered in Columns (3)-(6) by the interaction of our exposure measure with the Bund yield, which encompasses shocks to both short-term and long-term interest rates.

The estimated $\beta$ coefficient in Columns (1) and (2) is 0.002 and is statistically significant at the 1 percent level. Remarkably, Table 3 shows that the estimated impact of the capital flow shock on city output growth becomes stronger when we control for confounding factors. In particular, the strength of the capital flow shock impact is twice as large if we control for the confounding impact of the drop in the German Bund yield (Column 3), which itself can be affected by both

\footnotetext{
${ }^{28}$ By the same token, the finding shows how our new instrument can be potentially used to study the transmission of those different shocks.
} 
Table 3 BAnk Flows, Real Estate Exposure, and City Output Growth: REDUCED FORM ESTIMATES

\begin{tabular}{|c|c|c|c|c|c|c|c|c|}
\hline & $\begin{array}{c}(1) \\
\Delta \text { GDP }\end{array}$ & $\begin{array}{c}(2) \\
\Delta \text { GDP }\end{array}$ & $\begin{array}{c}(3) \\
\Delta \text { GDP }\end{array}$ & $\begin{array}{c}(4) \\
\Delta \text { GDP }\end{array}$ & $\begin{array}{c}(5) \\
\Delta \mathrm{GDP}\end{array}$ & $\begin{array}{c}(6) \\
\Delta \text { GDP }\end{array}$ & $\begin{array}{c}(7) \\
\Delta \text { GDP }\end{array}$ & $\begin{array}{c}(8) \\
\Delta \text { GDP }\end{array}$ \\
\hline Spread $_{t-1}$ & $\begin{array}{l}-0.133^{*} \\
(0.068)\end{array}$ & - & - & - & - & - & - & - \\
\hline Exposure $_{c, 2008} \times$ Spread $_{t-1}$ & $\begin{array}{c}0.002^{* * *} \\
(0.001)\end{array}$ & $\begin{array}{c}0.002^{* * *} \\
(0.001)\end{array}$ & $\begin{array}{c}0.004^{* * *} \\
(0.002)\end{array}$ & $\begin{array}{c}0.004^{* * *} \\
(0.001)\end{array}$ & $\begin{array}{c}0.004^{* * *} \\
(0.001)\end{array}$ & $\begin{array}{l}0.003^{* *} \\
(0.001)\end{array}$ & $\begin{array}{l}0.004^{* *} \\
(0.002)\end{array}$ & $\begin{array}{c}0.004^{* * *} \\
(0.002)\end{array}$ \\
\hline Exposure $_{c, 2008} \times$ Bund $_{t-1}$ & & & $\begin{array}{c}0.009 \\
(0.006)\end{array}$ & & & & $\begin{array}{c}0.009 \\
(0.006)\end{array}$ & $\begin{array}{c}0.009 \\
(0.006)\end{array}$ \\
\hline Exposure $_{c, 2008} \times$ Eonia $_{t-1}$ & & & & $\begin{array}{l}0.008^{* *} \\
(0.003)\end{array}$ & & & & \\
\hline Exposure $_{c, 2008} \times$ ECB Rate $_{t-1}$ & & & & & $\begin{array}{l}0.012^{* *} \\
(0.005)\end{array}$ & & & \\
\hline Exposure $_{c, 2008} \times \operatorname{VIX}_{t-1}$ & & & & & & $\begin{array}{c}0.001 \\
(0.001)\end{array}$ & & \\
\hline Pop $_{2008} \times$ Spread $_{t-1}$ & & & & & & & $\begin{array}{c}0.000 \\
(0.000)\end{array}$ & \\
\hline Pop. Dens. ${ }_{2008} \times$ Spread $_{t-1}$ & & & & & & & & $\begin{array}{l}-0.000 \\
(0.000)\end{array}$ \\
\hline Exposure $_{c, 2008}$ & $\begin{array}{c}-0.014^{* * *} \\
(0.005)\end{array}$ & - & - & - & - & - & - & - \\
\hline Time FE & No & Yes & Yes & Yes & Yes & Yes & Yes & Yes \\
\hline City FE & No & Yes & Yes & Yes & Yes & Yes & Yes & Yes \\
\hline Obs & 456 & 456 & 456 & 456 & 456 & 456 & 456 & 456 \\
\hline$R^{2}$ & 0.008 & 0.436 & 0.439 & 0.445 & 0.442 & 0.438 & 0.439 & 0.439 \\
\hline
\end{tabular}

NOTE. The regressions are based on annual city-level data over the period 2009-2014. The dependent variable is real GDP per capita growth. The regressors are the lagged values of the GIPS spread, the 2008 city-level value of our exposure measure, and the interaction between the two. The regression in Column (1) is without city or time fixed effects, Column (2) includes both. In Columns (3)-(6), we control for the interactions between the German 10-year Bund yield, the Eonia interbank rate, the ECB policy rate, and the VIX index and our exposure measure. Columns (7)-(8) add to the specification in Column (3) a control for the interaction between the GIPS spread and the 2008 level of city population or population density. Heteroskedasticity-robust standard errors clustered at the city level are shown in parentheses. ${ }^{*},{ }^{* *}$ and ${ }^{* * *}$ indicate statistical significance at the $10 \%, 5 \%$, and $1 \%$ levels, respectively.

the policy rate and interbank conditions, as well as the Bund term premium. Restricting attention to the European interbank market (in Column 4) or the ECB's monetary policy (in Column 5), as measured by the Eonia rate and the ECB policy rate, respectively, we see that the size of the GIPS spread impact remains constant at 0.004. Interestingly, in these regressions, the separate impact of the ECB rate or the Eonia is estimated precisely and, not surprisingly, is larger than the impact of the capital flow shock. These results shows that tighter real estate markets could amplify both interbank and monetary policy shocks. However and most importantly, these results show that monetary policy and other common factors in the European interbank market, or the German Bund market which subsumes all these factors, do not absorb the effects of the capital flow shock 
itself. Controlling for the VIX index and its interaction with our exposure measure, as is often done in the extant literature, weakens slightly our results, as the GIPS spread and the VIX moved together after the peak of the European crisis (see Panel B, Figure 1). Unlike the Eonia rate or the ECB rate, the VIX index, however, does not play an independent explanatory role.

The results in Columns (7) and (8) show that the magnitude of the estimated coefficient is unchanged when we control for city demographic characteristics, even though the statistical significance of the $\beta$ estimate decreases slightly in Column (7). In fact, the city population share is the main criterion for the city allocation of refugees (Table 2) and it is tightly correlated with the share of refugees. Neither population share or population density, however, play a separate role in explaining the differential impact of the capital flow shock on city growth, conditional on the bank flow shock that we identify. ${ }^{29}$

The economic magnitude of the estimated impact is sizable. For the most conservative specifications presented in Columns (7)-(8), in which we control for both the presence of other common shocks and city demographics, we find the largest value of the parameter of interest. This value implies that, for every 100-basis points increase in the GIPS spread, output growth in cities at the 75th percentile of the exposure distribution (e.g., Magdeburg) is, on average over the sample period, 22 basis points higher than in cities at the 25 th percentile (e.g., Leverkusen) ${ }^{30}$ Considering an average increase in the GIPS spread over our sample period of 360 basis points, these estimates imply that cities most exposed to real estate market tightness might have grown 79 basis points more per year than the least exposed cities during that period. The estimated impact falls to 39.5 basis points if we use the lower estimate of 0.002 in Column (2) of Table 3 without additional controls. Thus, our main result implies that cities most exposed to real estate market tightness grew about 40-80 basis points more per year than the least exposed ones during 2009-2014, 2.4-4.8 percentage points more cumulatively between 2009 and 2014.

\footnotetext{
${ }^{29}$ In unreported regressions, we also controlled for the differential impact of the bank flow shock across East and West German cities by interacting an East Germany dummy with the GIPS spread and our exposure measure. The triple interaction was insignificant, indicating that there is no statistically different impact in the East and West. Standard test statistics for the detection of residual spatial correlation cannot reject the null of no correlation for a reasonably wide range of settings of the weighting matrix parameters.

${ }^{30}$ Cities at the 75 th percentile of the distribution have an exposure value of 80 . Thus, the output growth effect of a 100 -basis points GIPS spread change is $32=(100 * 80 * 0.004)$ basis points. In contrast, cities at the 25 th percentile have an exposure value of 25 . Hence, in this case, the impact is a mere $10=(100 * 25 * 0.004)$ basis points.
} 


\subsection{Instrumental Variable Estimates}

The reduced form estimates in Table 3 yield evidence on the importance of real estate market tightness for output growth, but are silent on the specific role that residential or commercial property prices may play in the transmission mechanism. To shed light on the mediating role of property prices in the transmission of bank flow shocks, similar to Chaney et al. (2012), we now regress city output growth on property prices, instrumenting the latter with the interaction of the GIPS spread with our main exposure measure. ${ }^{31}$ So we next present the first and second stage econometric specifications and corresponding results in turn.

\subsubsection{First Stage}

Table 4 reports a battery of alternative first stage regressions. The first stage regression specification is

$$
\operatorname{REP}_{c, t}=\alpha_{c}+\alpha_{t}+\gamma \cdot \operatorname{INST}_{c, t-1}+\eta_{c, t}
$$

where $\mathrm{REP}_{c, t}$ is either the commercial property price index $(C R E P)$ or the residential price index $(R R E P)$, and $I N S T_{c, t-1}$ is the instrumental variable. All regressions are saturated with time and city fixed effects. In Columns (1) and (2), the instrumental variable is our main instrument, $\left(\operatorname{Spread}_{t-1} \times\right.$ Exposure $\left._{c, 2008}\right)$, as it was used in the reduced form estimates reported in Table 3. It is the same variable in both sector regressions. The results reported in Columns (1) and (2) show that our exposure measure is a very good predictor of property prices in the commercial sector, with a F-statistic well above the norm, even after controlling for city and time fixed effects, but not in the residential sector, where the F-statistic is below acceptable levels.

As we discussed earlier and in line with our model in the Appendix, this result is theoretically plausible. In order to avoid drawing inference based on a weak instrument, and also to evaluate the relative importance of the two real estate sectors in the transmission mechanism of the bank flow shock simultaneously, we use the alternative instrument discussed earlier. In Columns (3) and (4),

\footnotetext{
${ }^{31}$ Chaney et al. (2012) interact the aggregate mortgage interest rate (our spread) with the housing supply elasticity of Saiz (2010) (our exposure measure) and then use the predicted component of local real estate prices to estimate their mediating effect on firm investments in response to this common shock.
} 
Table 4 BAnk Flows, Real Estate Exposure, AND Property Prices: FIRST STAGE RESULTS

\begin{tabular}{lcccccc}
\hline \hline & $(1)$ & $(2)$ & $(3)$ & $(4)$ & $(5)$ & $(6)$ \\
& $R R E P$ & $C R E P$ & RREP & CREP & RREP & CREP \\
\hline Spread $_{t-1} \times$ Exposure $_{c, 2008}$ & $0.006^{*}$ & $0.012^{* * *}$ & & & 0.001 & $0.009^{* * *}$ \\
& $(0.003)$ & $(0.002)$ & & & $(0.003)$ & $(0.002)$ \\
Spread $_{t-1} \times{\text { Share } 25-30_{c, 2008}}$ & & & $0.562^{* * *}$ & $0.481^{* * *}$ & $0.546^{* * *}$ & $0.381^{* * *}$ \\
& & & $(0.086)$ & $(0.096)$ & $(0.084)$ & $(0.085)$ \\
Time FE & Yes & Yes & Yes & Yes & Yes & Yes \\
City FE & Yes & Yes & Yes & Yes & Yes & Yes \\
\hline F-Statistic & 2.9 & 38.9 & 42.8 & 25.0 & 23.4 & 31.8 \\
Obs & 456 & 456 & 456 & 456 & 456 & 456 \\
$R^{2}$ & 0.790 & 0.792 & 0.829 & 0.797 & 0.829 & 0.813 \\
\hline \hline
\end{tabular}

Note. The table reports the estimation results for the first stage. The regressions are based on annual city-level data from 2009 to 2014. The dependent variables are the residential and commercial real property price indexes. The regressors are the lagged value of the GIPS spread interacted with the 2008 value of the exposure measure in Columns (1) and (2), and the GIPS spread interacted with the 2008 value of the city share of population aged 25-30 in Columns (3) and (4). Columns (5) and (6) include both candidate instruments in each equation. All regressions include city and time fixed effects. The hetroskedasticity-robust standard errors clustered at the city level are shown in parentheses. ${ }^{*}$, ${ }^{* *}$ and ${ }^{* * *}$ indicate statistical significance at the $10 \%, 5 \%$, and $1 \%$ levels, respectively.

we report estimates for the same specification as in equation 3, but use the interaction between the GIPS spread and the share of population in the age bracket $25-30$, denoted $\left(\operatorname{Spread}_{t-1} \times\right.$ Share 25-30 $c$ 2008), as instrument in both sector regressions. The results reported in Columns (3) and (4) show that this alternative instrument has good predictive power for both sectors, even though the F-statistic is now weaker in the commercial sector. ${ }^{32}$

In Columns (5) and (6) of Table 4, we use both instruments at the same time in each property sector. The results show that only the city share of people aged 25-30 in 2008 interacted with the GIPS spread predicts differences in residential property prices, while both candidate instruments are good predictors of price differences across cities in the commercial sector. In both the residential and the commercial sector, the F-statistic is well above conventional levels. Note, here, that the magnitude of the coefficient on our exposure measure in Column (6) is only slighter smaller than when exposure is entered alone in Column (2), while the $R^{2}$ is marginally higher. In contrast, in

\footnotetext{
${ }^{32}$ Note here that we obtain these results only with the city share of population aged 25-30, but not with the share of people aged 18-25. The results are also weaker when we use the next age bracket (age of 30-50). One interpretation is that people aged 18-25 in Germany typically go to university. During this period, young people typically leave parents or live on university campuses and are less likely to rent in the open market. As the age bracket increases, the composition is more likely to shift toward buyers.
} 
the residential sector, when we use both instruments, the effect of our exposure measure is soaked up by the share of young population. Equipped with these first stage results, we proceed to report our instrumental variable estimation results.

\subsubsection{Second Stage}

In the second stage, we estimate the impact of property price changes triggered by capital flow shocks on output growth. We consider three alternative specifications. The first, following Chaney et al. (2012), estimated with two-stage least squares (2SLS), evaluates the role of residential and commercial property prices separately:

$$
\Delta G D P_{c, t}=\alpha_{c}+\alpha_{t}+\delta \cdot \mathrm{REP}_{c, t}+\varepsilon_{c, t}
$$

where the instrument for $\operatorname{CREP}_{c, t-1}$ is $\left(\operatorname{Spread}_{t-1} \times\right.$ Exposure $\left._{c, 2008}\right)$ and the instrument for $\operatorname{RREP}_{c, t-1}$ is $\left(\operatorname{Spread}_{t-1} \times\right.$ Share $\left.25-30_{c, 2008}\right)$. This first specification is also estimated instrumenting each property price index with both instrumental variables, so that the estimated parameter is overidentified. In this specification, bank flows, as captured by the GIPS spread, can affect city output growth via the predicted component of city property price variations with a strength that depends on the tightness of the local real estate market, captured by our exposure measure in the commercial sector and by the city share of young people in the residential sector. Implicit in this specification is the assumption that the error terms of the residential and the commercial price equations are uncorrelated.

The second specification is

$$
\Delta G D P_{c, t}=\alpha_{c}+\alpha_{t}+\delta^{P} \cdot \operatorname{RREP}_{c, t}+\delta^{C} \cdot \mathrm{CREP}_{c, t}+\varepsilon_{c, t}
$$

where the instruments are $\left(\operatorname{Spread}_{t-1} \times\right.$ Share $\left.25-30_{c, 2008}\right)$ for residential prices and $\left(\operatorname{Spread}_{t-1} \times\right.$ Exposure $_{c, 2008}$ ) for commercial prices. This second specification, also estimated with 2SLS, permits assessing the relative importance of the residential and commercial sectors in the transmission of the bank flow shocks captured by the GIPS spread. 
The third specification, estimated with 3SLS, is based on the following system of seemingly unrelated regressions:

$$
\begin{aligned}
& \operatorname{RREP}_{c, t}=\alpha_{c}+\alpha_{t}+\gamma^{R} \cdot\left(\operatorname{Spread}_{t-1} \times \text { Share } 25-30_{c, 2008}\right)+ \\
& \alpha^{R R} \cdot \operatorname{RREP}_{c, t-1}+\alpha^{R C} \cdot \operatorname{CREP}_{c, t-1}+\eta_{c, t} \\
& \operatorname{CREP}_{c, t}=\alpha_{c}+\alpha_{t}+\gamma^{C} \cdot\left(\operatorname{Spread}_{t-1} \times \text { Exposure }_{c, 2008}\right)+ \\
& \alpha^{R C} \cdot \operatorname{RREP}_{c, t-1}+\alpha^{C C} \cdot \mathrm{CREP}_{c, t-1}+\eta_{c, t} \\
& \Delta G D P_{c, t}=\alpha_{c}+\alpha_{t}+\delta^{R} \cdot \operatorname{RREP}_{c, t}+\delta^{C} \cdot \mathrm{CREP}_{c, t}+\varepsilon_{c, t} .
\end{aligned}
$$

which takes into explicit account the contemporaneous or lagged correlation between the residential and the commercial real estate sectors.

Table 5 reports the estimation results. In Columns (1)-(4), the specification is as in equation (4). That is, in Columns (1) and (2), we instrument residential prices with $\left(\operatorname{Spread}_{t-1} \times\right.$ Share $\left.25-30_{c, 2008}\right)$ and commercial prices with $\left(\operatorname{Spread}_{t-1} \times\right.$ Exposure $\left._{c, 2008}\right)$ as in Columns (2) and (3) of Table 4. In Columns (3) and (4), we use both instruments for each sector as in Columns (5) and (6) of Table 4. In Column (5), we run a horse race between the two sectors by assigning an instrument to each variable as in equation (5). In Column (6), we run the same horse race by using the 3SLS system estimates in equations (6)-(8). All regressions are saturated with time and city fixed effects.

The results in Table 5 suggest that both commercial and residential property prices variations predicted by changes in the GIPS spread can affect city output growth, although the magnitude of the impact is seemingly larger and estimated more precisely in the commercial sector (Columns 1 and 2). The results are virtually unchanged when we overidentify the parameters of interest by using both instruments in each regression (Columns 3 and 4).

Column (5) reports the 2SLS estiamte for the output equation when we horse race the two sectors including both the residential and commercial property prices at the same time, as in equation (5), and assigning one relevant instrument to each variable. When we put both residential and commercial prices in the regression, we find that the coefficient on the residential prices looses 
Table 5 City Output Growth AND Property Prices: INSTRUMENTAL VARIABLES RESULTS

\begin{tabular}{lcccccc}
\hline \hline & 2SLS & 2SLS & 2SLS & 2SLS & 2SLS & 3SLS \\
\hline \hline & $(1)$ & $(2)$ & $(3)$ & $(4)$ & $(5)$ & $(6)$ \\
& $\Delta$ GDP & $\Delta$ GDP & $\Delta$ GDP & $\Delta$ GDP & $\Delta$ GDP & $\Delta$ GDP \\
\hline RREP $_{t}$ & $0.122^{*}$ & & $0.130^{* *}$ & & -0.025 & -0.076 \\
& $(0.062)$ & & $(0.062)$ & & $(0.092)$ & $(0.047)$ \\
CREP $_{t}$ & & $0.160^{* * *}$ & & $0.151^{* * *}$ & $0.172^{*}$ & $0.095^{* *}$ \\
& & $(0.059)$ & & $(0.056)$ & $(0.089)$ & $(0.044)$ \\
Time FE & Yes & Yes & Yes & Yes & Yes & Yes \\
City FE & Yes & Yes & Yes & Yes & Yes & Yes \\
\hline Over. Ident. (p-val.) & - & - & 0.10 & 0.78 & - & - \\
Obs & 456 & 456 & 456 & 456 & 456 & 456 \\
$R^{2}$ & 0.410 & 0.416 & 0.408 & 0.419 & 0.418 & 0.435 \\
\hline \hline
\end{tabular}

Note. This table reports instrumental variable estimates. The regressions are based on annual city-level data from 2009 to 2014 without city states. The dependent variable is real per capita GDP growth. The main regressors are the real commercial and residential property price indexes. In Column (1), we instrument residential prices by the interaction term between the lagged GIPS spread and the 2008 value of the city share of people aged 25-30. In Column (2), commercial prices are instrumented by the interaction between the lagged GIPS spread and the 2008 value of our exposure measure. Columns (3) and (4) employ both instruments at the same time with overidentification restrictions that are valid (p-values of the corresponding test statistics also reported). In Column (5), we include both residential and commercial property prices in the same regression as in equation (5), using the relevant instrument for each of these two variables. In Column (6), we estimate the same regression as in Column (5), but using 3SLS on the system of seemingly unrelated regressions in equations (6)-(8). All regressions include city and time fixed effects. The heteroskedasticityrobust standard errors clustered at the city level are shown in parentheses. ${ }^{*},{ }^{* *}$ and ${ }^{* * *}$ indicate statistical significance at the $10 \%, 5 \%$, and $1 \%$ levels, respectively.

its economic and statistical significance, while the coefficient on commercial prices increases in magnitude but is now estimated less precisely. These results are validated by the 3SLS estimates in Column (6) that yield a slightly smaller impact through commercial prices, but more precisely estimated. In contrast, the impact through the residential sector vanishes. This is strong empirical evidence that commercial property prices are more important than residential prices in the transmission of the bank flow shock we focused on. ${ }^{33}$

These estimates can fully account for our reduced form findings. We saw earlier that, based on the reduced form estimate of our model, a 100-basis points GIPS spread increase leads to a 10 basis

\footnotetext{
${ }^{33}$ The empirical finding begs the question of why, in contrast to the experience of the United States and several other countries, the residential real estate sector does not seem to have an impact on output growth during the German housing boom. While investigating this properly is beyond the scope of this paper, one possible answer is that the German housing boom is not associated with a credit boom through the end of our sample period in 2014. An interesting open question is whether this is a more general feature of cash-based housing booms, as for instance when they are driven by foreign investors or deep-pocket domestic investors.
} 
points higher real GDP growth rate in cities most exposed to real estate market tightness, based on the lower-end of the range of our point estimates of 0.002, obtained without additional controls in Column (2) of Table 4. The second stage estimates reported in Table 5 suggest that commercial property price increases triggered by GIPS spread changes can account for all of this differential. To see this, multiply the first stage coefficient in Column (2) of Table $4(=0.012)$ by the secondstage estimate in Column (2) of Table $5(=0.160)$. The resulting product is 0.0019 , essentially the same as the reduced form estimate. This finding suggests that commercial property prices are at the heart of the transmission mechanism of the bank flow shock in cities more exposed to real estate market tightness, possibly reflecting the working of a collateral channel of transmission.

In sum, the evidence reported in this section establishes that (i) tighter real estate markets as captured by our exposure measure are associated with a stronger impact of bank inflows on local economic activity, and (ii) commercial property price differences across cities triggered by bank flow shocks can account for the whole of this differential impact. This is evidence that the bulk of the estimated reduced form effect goes through the commercial sector. In light of this, when we open up the black box of the transmission mechanism underlying the estimated differential impact of bank flow shocks across cities, in the rest of the paper, we will focus only on the commercial sector, exploring empirically the collateral channel on the firm side.

\section{Bank Flows, Real Estate Collateral, and Credit Supply}

In this section, we study the role of real estate collateral in the credit allocation to firms following a bank flow shock. Figure 6 plots average credit growth during the 2009-2014 period by 2-digit NAICS classification against the average share of tangible assets in the same sector $(T S)$. The figure shows that, on average during this period, all sectors experienced a sharp credit contraction, consistent with the aggregate picture in Panel D of Figure 1. However, it also suggests a positive and tight association between faster (slower) credit growth (decline) and the availability of real estate collateral, with sectors typically using land and structures more intensively, such as Agriculture, Real Estate itself, Transport and Warehousing, Accommodation and Recreation, experiencing higher (lower) credit growth (decline). 
Figure 6 Credit Growth and Real Estate Collateral by Sector

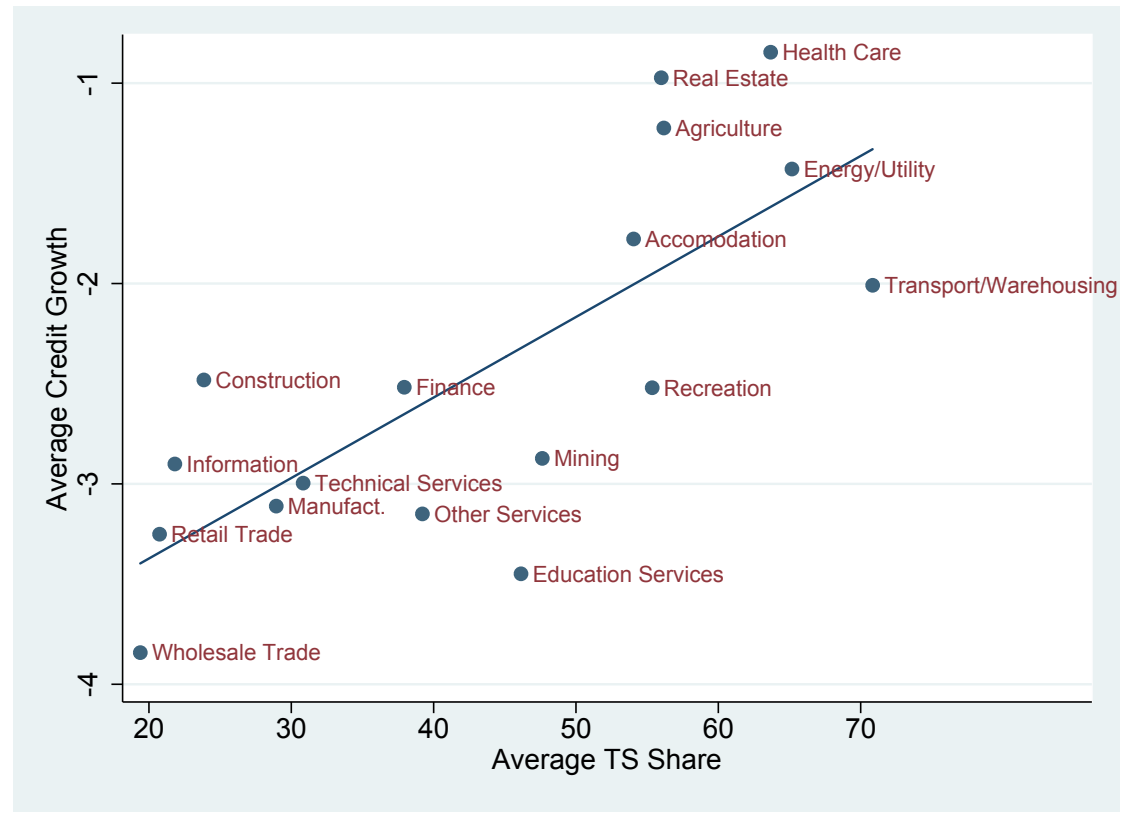

NoTE. The figure plots average credit growth against average tangible fixed assets over total assets (TS), by industry. The industry classification corresponds to the 2-digit NAICS code, with the following adjustments: Manufacturing equals codes 31-33; Retail Trade equals codes 44-45; Transport and Warehousing equal codes 48-49; and Technical Services equal codes 54-56. The correlation between the two variables is $75 \%$ with a p-value of 0 . The sample period is $2009-2014$.

Consistent with micro evidence on the role of collateral in financial contracting (e.g., Benmelech, Garmaise and Moskowitz (2005) and Benmelech and Bergman (2008)), we conjecture that an increase in the domestic credit supply associated with repatriation of foreign assets should benefit more firms and sectors with more real estate collateral, as this form of lending is safer and easier to screen, price and monitor. This hypothesis also accords with related evidence on the impact of capital flow shocks on the domestic credit supply reviewed in Section 1.

We saw earlier that a higher GIPS spread is associated with a reduction in German bank holdings of foreign assets in the rest of the euro area and a lower aggregate domestic lending-deposit spread. Here, we focus on the allocation of domestic credit at the bank-firm level associated with changes in the GIPS spread. As we discussed in Section 2, our bank-firm level proxy for real estate collateral is the share of tangible fixed assets in total assets, or "share of tangible assets" for brevity. To address endogeneity concerns, in this step of the analysis, we rely on the microeconomic nature of our bank-firm-relationship data, assuming that no such individual relationship can 
affect the GIPS spread, and that the quantity of real estate collateral at the bank-firm-relationship level is predetermined with respect to lending decisions.

Specifically, to assess the role of real estate collateral in the credit allocation to firms, following Behn, Haselmann and Wachtel (2016), who use German credit register data to study the impact of capital regulation on credit supply, we estimate the following reduced form regression:

$$
\Delta \mathrm{L}_{i, j, t}=\alpha_{i, t}+\alpha_{j, y e a r}+\beta \cdot\left(\operatorname{SPREAD}_{t-1} \times \mathrm{TS}_{j, t-4}\right)+\varepsilon_{i, j, t},
$$

where $\Delta L_{i, j, t}$ is the log-change in loan volume of bank $i$ to firm $j$ in quarter-year $t$, and $\left(\operatorname{SPREAD}_{t-1} \times\right.$ $\left.\mathrm{TS}_{j, t-4}\right)$ is the lagged interaction term between the GIPS spread and firm $j$ 's share of tangible assets, $\mathrm{TS}_{j, t-4 .}{ }^{34}$ In order to control for unobserved time-varying heterogeneity at the bank level, we include bank-year-quarter fixed effects $\left(\alpha_{i, t}\right)$. To control for year-on-year changes in loan demand and for the location of firms' headquarters that might influence firms' credit access, we include firm-year fixed effects $\left(\alpha_{j, y e a r}\right)$. Finally, by clustering the standard errors at the bank-firm level, we allow the observations to be correlated across bank-firm relationships. The coefficient of interest is $\beta$, which captures the differential firm credit access in response to the bank flow shock.

Table 6 summarizes the baseline results, as in equation (9), and reports a number of robustness checks. The positive and highly statistically significant estimate of $\beta$ in Column (1) suggests that a higher GIPS spread leads to more bank lending to firms with more real estate collateral, controlling for loan demand with firm-year fixed effects. The magnitude of this effect is economically significant: a 100-basis points GIPS spread increase raises (slows) the quarterly rate of credit growth (decline) of high-TS firms (at the 75th percentile of the distribution) by 74 basis points more than the corresponding growth rate of low-TS firms (at the 25th percentile). ${ }^{35}$

Column (2) of Table 6 interacts the GIPS spread with the average share of tangible assets across industries. The motivation behind this specification is that industry-specific characteristics can affect the level and nature of firms' real estate asset holdings (see, for instance, Rochdi (2015)). In addition, the average industry share of tangible assets is less likely to be endogenous with

\footnotetext{
${ }^{34}$ The tangible asset ratio is lagged by four quarters because firm-level data are annual, while bank data are quarterly.

${ }^{35} \mathrm{We}$ calculate these magnitudes as follows. The 25 th percentile of the distribution of $T S$ is $8.74 \%$. The corresponding value for the 75 th percentile is $65.52 \%$. Thus, the credit growth difference between both types of firms is: $(65.52-8.74) * 0.013=0.74$.
} 
Table 6 Bank Flows, Real Estate Collateral, And Firm Credit Access

\begin{tabular}{|c|c|c|c|c|c|}
\hline & $\begin{array}{l}(1) \\
\Delta \mathrm{L}\end{array}$ & $\begin{array}{l}(2) \\
\Delta \mathrm{L}\end{array}$ & $\begin{array}{l}(3) \\
\Delta \mathrm{L}\end{array}$ & $\begin{array}{l}(4) \\
\Delta \mathrm{L}\end{array}$ & $\begin{array}{l}(5) \\
\Delta \mathrm{L}\end{array}$ \\
\hline Spread $_{t-1} \times \mathrm{TS}_{t-4}$ & $\begin{array}{c}0.013^{* * *} \\
(0.003)\end{array}$ & & & & \\
\hline $\operatorname{Spread}_{t-1} \times \mathrm{TS}_{\text {Industry }, t-4}$ & & $\begin{array}{r}0.014^{* * *} \\
(0.003)\end{array}$ & & & \\
\hline Spread $_{t-1} \times\left(\mathrm{TS}_{2008} * \mathrm{CREP}_{t-4}\right)$ & & & $\begin{array}{l}0.011^{* *} \\
(0.005)\end{array}$ & & \\
\hline Spread $_{t-1} \times \mathrm{TS}_{t-4} \times$ Interbank $_{t-1}$ & & & & $\begin{array}{l}0.467^{* *} \\
(0.231)\end{array}$ & \\
\hline $\mathrm{TS}_{t-4} \times$ Interbank $_{t-1}$ & & & & $\begin{aligned}-3.832^{* *} \\
(1.813)\end{aligned}$ & \\
\hline Spread $_{t-1} \times \mathrm{TS}_{t-4} \times$ Net Foreign Assets $_{t-1}$ & & & & & $\begin{array}{l}0.030^{*} \\
(0.017)\end{array}$ \\
\hline $\mathrm{TS}_{t-4} \times$ Net Foreign Assets ${ }_{t-1}$ & & & & & $\begin{array}{c}-0.370^{* * *} \\
(0.122)\end{array}$ \\
\hline Firm-Year FE & Yes & Yes & Yes & No & No \\
\hline Firm-Year-Quarter FE & No & No & No & Yes & Yes \\
\hline Bank-Year-Quarter FE & Yes & Yes & Yes & Yes & Yes \\
\hline Obs & 573,985 & 707,742 & 188,965 & 387,734 & 514,985 \\
\hline$R^{2}$ & 0.141 & 0.145 & 0.147 & 0.456 & 0.430 \\
\hline
\end{tabular}

Note. The regressions are based on quarterly bank-firm-relationship level data over the period 2009:Q1-2014:Q4. The dependent variable is the log-difference in loan volume of bank $\mathrm{i}$ to firm $\mathrm{j}$ in quarter-year pair $\mathrm{t}$. The independent variable is the GIPS spread interacted with firms' share of tangible assets. The latter is replaced by its industry mean in Column (2). In Column (3), we inflate the pre-determined 2008 share of firm-level tangible assets with the city-level real commercial real estate price index. Columns (1)-(3) include bank-time and firm-year fixed effects. Column (4) interacts the GIPS spread with firm-level tangible assets and the interbank funding over retail deposits ratio. Column (5) interacts the spread with tangible assets and banks' net foreign assets vs. euro area countries over total assets. In Columns (4) and (5), we replace firm-year with firm-year-quarter fixed effects. The standard errors are clustered at the bank-firm level and shown in parentheses. ${ }^{*},{ }^{* *}$ and ${ }^{* * *}$ indicate statistical significance at the $10 \%, 5 \%$, and $1 \%$ levels, respectively. 
respect to other firm characteristics or lending at the bank-firm level. Column (2) indicates that our results are robust to using the industry average of tangible assets. In particular, we find that banks shift credit towards firms in industries with higher shares of tangible assets. The results are virtually unchanged if we use the median industry value instead (not reported).

The specification in Column (3) holds the firm share of tangible assets fixed at its 2008 level and inflates it with the city-level commercial real property price index, assuming that firms own most of their real estate assets in the city where their headquarters are located, in a manner similar to Chaney et al. (2012) and Doerr (2018). Again, we find that banks shift their credit supply towards firms with more real estate collateral, even though the $\beta$ coefficient is now estimated less precisely. This might be the case because of the lower number of observations in this experiment, as the variable CREP is not available for all cities covered by the German credit registry, leading to a sample size that is roughly half the one used in the baseline specification.

The role of two important bank characteristics is explored in Columns (4)-(5). Specifically, first we examine whether the role of collateral is stronger for banks with higher interbank-todeposit ratios. As this type of funding is more likely to be exposed to international capital market fluctuations, banks with a higher share of non-deposit funding should be more affected by changes in the GIPS spread, which captures also changes in global financial conditions. Second, we also examine the role of individual-bank pre-GFC exposure to the rest of the euro area as captured by the net foreign assets position vs the rest of the euro area as a share of total assets in 2006. If the GIPS spread is capturing bank retrenchment from Southern Europe, we should find that banks with a higher pre-GFC exposure to the rest of the euro area respond more to the spread change. To this end, we include two triple interaction terms. The first is the interaction between the GIPS spread, the share of tangible assets, and the lagged interbank-to-deposit funding ratio (Column 4). The second term interacts the spread with the share of tangible assets and the lagged value of the share of net foreign assets (Column 5).

In these two additional regressions, the granularity of the credit register data permits us to restrict the sample to firms with multiple bank relationships, and hence allowing us to include firm-year-quarter fixed effects $\left(\alpha_{j, t}\right)$, as opposed to firm-year fixed effects as before. As shown 
by Khwaja and Mian (2008), this strategy fully absorbs firm-specific loan demand shocks. ${ }^{36}$ The estimation results in Column (4) indicate that the sensitivity of credit supply to real estate collateral is stronger for banks with a higher non-core funding ratio, as can be gauged from the positive and statistically significant coefficient on the triple interaction term. The results in Column (5) suggest that lending might also be affected by the initial euro area exposure, even though this effect is statistically significant only at the $10 \%$ level.

Appendix Table B.2 reports additional robustness checks. The results in Table 6 are robust to augmenting the baseline regression with the interaction between the GIPS spread and other firm-level controls that are likely to be correlated with the firm share of tangible assets (Columns (1)-(3)). This additional experiment ensures that the baseline results are not driven by a correlation between the share of tangible assets and other firm-level characteristics. The results show that, if anything, adding more firm-level controls interacted with the GIPS spread increases the economic magnitude of the estimated coefficient on the key interaction term between the GIPS spread and tangible assets. In Column (4) of Table B.2, we drop observations during the 2009-2010 period. This might be important because the German government, after the GFC, provided guarantees to certain firms and sectors. To the extent to which these guarantees are correlated with the tangible asset ratio of firms, our baseline results could be biased. The results in Column (4) show that, even excluding 2009-2010, a higher GIPS spread leads to a shift in credit supply towards high-tangible asset firms. Finally, in Column (5), we document that our results are also robust to employing a time-invariant level of TS, measured in 2008, without inflating the initial level with commercial property price changes.

To sum up, Table 6 documents the role of real estate collateral in firms' access to credit in response to bank flow shocks. The results suggest that banks allocate more credit to firms with more real estate collateral, even after controlling for loan demand. This effect is stronger for riskier banks with higher interbank funding ratios or a greater net foreign asset exposure inside the Euro Area. The estimation results are robust to using the industry, rather than the individual, share of tangible assets, to employing the initial level of tangible assets, or to excluding from the

\footnotetext{
${ }^{36}$ Recall that we can employ this identification strategy because $92 \%$ of the firms in the German credit register borrow from more than one bank. Note here that, in these two specifications, firm-time fixed effects absorb the double interaction term between the GIPS spread and the tangible asset ratio, which therefore cannot be included separately.
} 
sample the period of government stimulus via credit guarantees.

The results are also robust to aggregation by sectors. Results reported in previous versions of this paper show that credit increases (declines) the fastest (the slowest) in industries with the highest shares of tangible assets. As we saw earlier, these sectors are those in which land and buildings are used more intensively in the production of their output (Figure 6). Specifically, credit growth is

highest in Agriculture, Energy and Utility, Transport and Warehousing and Real Estate itself-the industries with the highest average shares of tangible assets in total assets. In contrast, the results show that the information sector, which has one of the lowest shares of tangible fixed assets and whose production function is intensive in intangible assets, receives a significantly lower share of credit in response to bank inflows. This industry-level evidence is thus fully consistent with our bank-firm level evidence and suggests that firms with more real estate collateral have easier access to credit in response to bank flow shocks. Or, in other words, banks allocate disproportionately more credit to firms and sectors with more real estate collateral. This evidence is in strong accord with a transmission mechanism of bank flow shocks to output in which real estate collateral plays a critical role, as established in Section 4.

\section{Firm and Industry Outcomes}

Having established that retrenching banks supplied more credit to firms with more real estate collateral, in this section, we want to evaluate the role of collateral in determining the differential impact of a bank flow shock on firm and industry-level outcomes. We focus on employment, investment, total factor productivity (TFP), and borrowing costs. We then also evaluate whether bank flow shocks are associated with capital misallocation.

We measure borrowing cost changes, $\triangle I N T E X P$, with the log difference of firm interest expenses as a share of total debt as in Bernile et al. (2017). Employment growth, $\triangle E M P L$, is the rate of growth in the total number of employees. Investment, $\Delta K$, is the change in firm total fixed assets as a share of total assets, so as to make sure that the results are not driven by firm size. TFP growth, $\triangle T F P$, is constructed by estimating a production function based on our firm-level data, aggregated at the industry level at the second digit of the NAICS code, following Wooldridge 
(2009). Specifically, TFP is the residual of a regression of firm-level log real value added on log labor input (the log of the real wage bill), and log capital input (the log of the real book value of total fixed assets), where firm value added and the wage bill are deflated with the two-digit industry price deflators from the OECD STAN database. The capital stock is deflated by the price of investment goods. Some of the firm-level variables take extreme values. We therefore winsorize at the $1 \%$ level $\triangle I N T E X P$, as well as all variables used for the estimation of TFP before taking logs. Other firm variables are not winsorized, but the results would be essentially unchanged if we did winsorize them.

To evaluate the role of real estate collateral in the transmission of bank flow shocks to firms, we specify the following firm-level reduced form regression:

$$
\Delta \mathrm{Y}_{j, t}=\alpha_{j}+\alpha_{t}+\gamma \cdot \Delta \mathrm{Y}_{j, t-1}+v \cdot\left(\operatorname{SPREAD}_{t-1} \times \mathrm{TS}_{j, t-1}\right)+\varepsilon_{j, t},
$$

where $Y$ denotes alternative firm outcomes. As in the credit regression before, the main independent variable in all specifications is the GIPS spread interacted with the firm-level share of tangible assets. To mitigate endogenity concerns, we continue to rely on the microeconomic nature of the data, including firm and time fixed effects. In order to address concerns that firms may be on different trend paths, all regressions include the lagged dependent variable, $L D V$.

First, we expect bank flow shocks to reduce the borrowing costs of firms with a higher share of real estate collateral since these firms can obtain more credit on possibly better terms (Benmelech et al. (2005) and Benmelech and Bergman (2008)). ${ }^{37}$ Second, for consistency with our findings in Section 4, we should also find a positive coefficient on employment growth and investment in the transmission of a bank flow shock through the commercial real estate sector. In contrast, we do not have a firm prior on the impact on TFP of the bank flow shock.

Table 7 reports the results. Column (1) shows that bank flow shocks not only increase the credit supply to high-tangible asset firms, as shown before, but also reduce their borrowing costs, in line with the aggregate evidence reported in Table 1. Moreover, Columns (2)-(3) show that bank flow shocks increase employment and investment of high-tangible asset firms, with a statistically

\footnotetext{
${ }^{37}$ Unfortunately, the German credit registry does not include information on the price of credit contracted.
} 
Table 7 FIRM AND INDUSTRY OUTCOMES

\begin{tabular}{|c|c|c|c|c|c|c|}
\hline & Firm-Level & Firm-Level & Firm-Level & Firm-Level & Industry-Level & Industry-Level \\
\hline & (1) & (2) & (3) & (4) & (5) & (6) \\
\hline & $\triangle \mathrm{INTEXP}$ & $\triangle \mathrm{EMPL}$ & $\Delta \mathrm{K}$ & $\Delta \mathrm{TFP}$ & $\Delta \mathrm{TFP}$ & $\mathrm{SD}$ (TFP) \\
\hline Spread $_{t-1} \times \mathrm{TS}_{t-1}$ & $\begin{array}{c}-0.00021^{*} \\
(0.00)\end{array}$ & $\begin{array}{c}0.009^{* * *} \\
(0.00)\end{array}$ & $\begin{array}{l}0.144^{*} \\
(0.08)\end{array}$ & $\begin{array}{l}-0.002 \\
(0.01)\end{array}$ & - & - \\
\hline Spread $_{t-1} \times \mathrm{TS}_{\text {Industry }, t-1}$ & - & - & - & - & $\begin{array}{l}-0.016 \\
(0.02)\end{array}$ & $\begin{array}{l}0.005 \\
(0.03)\end{array}$ \\
\hline $\mathrm{TS}_{t-1}$ & $\begin{array}{c}0.004^{* *} \\
(0.00)\end{array}$ & $\begin{array}{l}-0.042 \\
(0.07)\end{array}$ & $\begin{array}{c}1.225^{* * *} \\
(0.34)\end{array}$ & $\begin{array}{c}0.386^{* * *} \\
(0.08)\end{array}$ & - & - \\
\hline $\mathrm{TS}_{\text {Industry }, t-1}$ & - & - & - & - & $\begin{array}{l}1.308 \\
(0.86)\end{array}$ & $\begin{array}{l}0.335 \\
(1.14)\end{array}$ \\
\hline $\mathrm{LDV}_{t-1}$ & $\begin{array}{c}-0.415^{* * *} \\
(0.01)\end{array}$ & $\begin{array}{c}-0.484^{* * *} \\
(0.03)\end{array}$ & $\begin{array}{l}0.031 \\
(0.03)\end{array}$ & $\begin{array}{c}-0.425^{* * *} \\
(0.03)\end{array}$ & $\begin{array}{c}-0.358^{* *} \\
(0.12)\end{array}$ & $\begin{array}{l}-0.024 \\
(0.21)\end{array}$ \\
\hline Firm FE & Yes & Yes & Yes & Yes & - & - \\
\hline Time FE & Yes & Yes & Yes & Yes & Yes & Yes \\
\hline Industry FE & - & - & - & - & Yes & Yes \\
\hline Obs & 20681 & 41827 & 50774 & 15143 & 64 & 64 \\
\hline$R^{2}$ & 0.326 & 0.364 & 0.031 & 0.389 & 0.340 & 0.735 \\
\hline
\end{tabular}

Note. The regressions in Columns (1)-(4) are based on annual firm-level data over the period 2009-2014. The dependent variables are: changes in firm borrowing costs, $\triangle I N T E X P$, measured as the log difference of firm interest expenses as a share of total debt in Column (1); employment growth, $\triangle E M P L$, measured as the rate of growth in the total number of employees in Column (2); investment, $\Delta K$, measured as the change in firm total fixed assets as a share of total assets in Column (3); TFP growth, $\triangle T F P$, constructed by estimating a production function based on our firmlevel data aggregated at the second digit of the NAICS code, following Wooldridge (2009). The independent variable is the GIPS spread interacted with the firm share of tangible assets. All specifications of Columns (1)-(4) include the respective lagged dependent variable, $L D V$, in addition to firm and time fixed effects. The standard errors are clustered at the industry-year level and are shown in parentheses. Columns (5)-(6) are industry level regressions in which the dependent variables are industry-level average total factor productivity growth, and the industry-level dispersion in total factor productivity. The main regressor here is the GIPS spread interacted with the industry average share of tangible assets. Both specifications include the lagged dependent variable, as well as time and industry fixed effects. Standard errors are clustered at the industry level. ${ }^{*},{ }^{* *}$ and ${ }^{* * *}$ indicate statistical significance at the $10 \%, 5 \%$, and $1 \%$ levels, respectively.

significance at the $1 \%$ and $10 \%$ level, respectively. Column (4) suggests that a higher firm share of tangible assets has a strong positive linear effect on TFP growth, with no differential impact on high-tangible asset firms during the episode of bank retrenchment that we consider. This is evident from the estimated coefficient on the level of lagged firm TS, which is positive and highly significant, and the insignificant coefficient on the interaction term. In other words, Column (4) says that bank flow shocks are not associated with a disproportionate increase or reduction in TFP growth of high-tangible asset firms. This result suggests that there was no capital misallocation during the bank repatriation episode that we study.

To investigate further this hypothesis, we first aggregate our firm-level data at the NAICS2 code industry level as in Doerr (2018). We then regress average industry TFP growth rates on the 
interaction between the GIPS spread and average industry-level shares of tangible assets, controlling for lagged TFP growth in addition to time and industry fixed effects. Column (5) shows that, as in the firm regression in Column (4), there is no significant association between the bank flow shock and a disproportionate change in TFP of high-tangible asset industries.

Second, we also regress the industry-level TFP dispersion on the interaction between the GIPS spread and the industry-level average share of tangible assets. Following Hsieh and Klenow (2009), the idea here is that, if credit growth leads to capital misallocation, TFP dispersion across firms in the same industry should increase with the bank flow shock, especially in industries with more real estate collateral that obtained a more than proportional share of the declining credit volumes during the 2009-2014 period. Column (6) shows that the estimated coefficient on this interaction term is positive, but clearly statistically insignificant. Even though this last regression is run with very few observations, the finding is consistent with the results of Gopinath et al. (2017), who do not uncover evidence of misallocation in Germany in the run up to the GFC when German capital was flowing abroad through its banking system. ${ }^{38}$ In an unreported regression, we also regressed TFP dispersion on the GIPS spread, without interacting the latter with industry-level average tangible asset ratios, finding no association between the GIPS spread and industry-level TFP dispersion.

These results stand in contrast to some other findings in the misallocation literature, specifically focused on housing booms. For example, Doerr (2018) shows that when property and land prices increase, firms with larger real estate holdings hire, invest, and produce more, but are less productive than firms with smaller real estate holdings in a sample of US public companies. Similarly, Martin, Moral-Benito and Schmitz (2018) find that Spanish banks more exposed to a real estate bubble initially lend relatively more to housing firms than non-housing firms. However, as the bubble persists, this composition effect disappears because housing credit repayments raise banks' net worth, supporting the credit access of all firms. In contrast, we show that bank retrenchment, while causing higher property prices with varying intensities across cities, is not associated with lower productivity growth at the firm or industry-level, or increased TFP dispersion. In the

\footnotetext{
${ }^{38}$ The result is unchanged if we replace TFP dispersion with the dispersion of the marginal product of capital. This is not surprising because, with the constant factor shares and a Cobb-Douglas production function, TFP dispersion and the dispersion of the marginal product of capital are proportional to each other (see Gopinath et al. (2017)).
} 
absence of a credit boom, the bank flow shock does not appear to be associated with lower TFP growth and capital misallocation. In fact, as we noted before, aggregate credit declined in real terms during the period we consider-see, for instance, Panel D in Figure 1.

To summarize, this last set of results accords well with the findings of Section 4 based on city-level data. The estimated impact of a bank flow shock on firm and industry-level outcomes provides additional evidence that real estate collateral plays a significant role. Real estate collateral seems critical not only for the differential access of firms and sectors to the increased credit supply triggered by bank inflows, but is also associated with increased hiring and investment, thus contributing to higher levels of local economic activity, without evidence of misallocation.

\section{Conclusions}

This paper studies the role of real estate markets in the transmission of bank flow shocks to city business cycles in Germany by using a new and unique matched city-level and bank-firm-level data set. Germany is an interesting laboratory because it experienced a sizable bank retrenchment episode with a real estate boom, but without a domestic credit boom, during and after the global financial crisis (GFC)

To identify the differential impact of bank flow shocks on output growth across German cities, we exploit the quasi-random geographic variation in a city-level measure of real estate market tightness or exposure. This measure is the product of the share of refugees in total refugees, which is determined by longstanding government rules and regulations at the city level, and a measure of non-developable area, which is determined by geography and land use regulations. As we show in the empirical analysis, this is an instrument that could also be used to study the impact of other common shocks across German cities, such as, for instance, the impact of the European Central Bank's monetary policy.

We find that the output growth impact of a bank flow shock, as measured by the sovereign bond spread of Southern European countries (the so-called GIPS spread), is more significant in cities that are more exposed to local real estate markets tightness. Our estimates imply that the cities most exposed to real estate market tightness, on average, grew 40-80 basis points more per year 
than the least exposed ones during 2009-2014, or 2.4-4.8 percentage points more cumulatively. Moreover, the differential response of commercial property prices across cities to the bank flow shock can account wholly for this growth differential.

The transmission mechanism that we uncover works through a collateral channel on the firm side, with commercial real estate playing a central role. We document the importance of real estate collateral for firm credit access and bank behavior by showing that German banks repatriated gross foreign assets from the rest of Europe after the GFC and lent disproportionately more to domestic firms and sectors with more tangible fixed assets. We also show that firms with more tangible assets hired and invested more in response to the bank flow shock. Consistent with the extant literature on Germany, but differently from studies of housing booms with credit booms, we do not find evidence of capital misallocation associated with the transmission of bank flow shocks across German cities.

While we find that, in response to the bank retrenchment shock we identify, the residential real estate sector has no significant impact on city output growth, our paper is ultimately silent on the causes of the German residential boom and its effects on output. Both the creditless nature of the boom with falling household leverage and the reduced form evidence on the predictive power of the city share of young people that we report are consistent with a cash-based buy-to-let hypothesis. Exploring drivers on residential house prices in the context of a portfolio re-balancing framework, like in Flavin and Yamashita (2002), and exploring its impact on consumption is an interesting area of future research. 


\section{References}

Adelino, Manuel, Antoinette Schoar, and Felipe Severino, "House prices, collateral, and selfemployment," Journal of Financial Economics, 2015, 117 (2), 288-306.

Aizenman, Joshua and Yothin Jinjarak, "Current account patterns and national real estate markets," Journal of Urban Economics, 2009, 66 (2), 75-89.

Badarinza, Cristian and Tarun Ramadorai, "Home away from home? Foreign demand and London house prices," Journal of Financial Economics, 2018, 130 (3), 532-555.

Baier, Andrea and Manuel Siegert, "Die Wohnsituation Geflüchteter. Kurzanalysen des Forschungszentrums Migration, Integration und Asyl des Bundesamtes für Migration und Flüchtlinge (Ausgabe 02/2018),” 2018.

Baskaya, Yusuf Soner, Julian di Giovanni, Sebnem Kalemli-Ozcan, and Mehmet Fatih Ulu, "International spillovers and local credit cycles," NBER Working Paper No. 23149, 2018.

Behn, Markus, Rainer Haselmann, and Paul Wachtel, "Procyclical capital regulation and lending," Journal of Finance, 2016, 71 (2), 919-956.

Benmelech, Efraim and Nittai K Bergman, "Liquidation values and the credibility of financial contract renegotiation: Evidence from US airlines," Quarterly Journal of Economics, 2008, 123 (4), 1635-1677.

_ , Mark J Garmaise, and Tobias J Moskowitz, "Do liquidation values affect financial contracts? Evidence from commercial loan contracts and zoning regulation," Quarterly Journal of Economics, 2005, 120 (3), 1121-1154.

Bernile, Gennaro, Vineet Bhagwat, and P Raghavendra Rau, "What doesn't kill you will only make you more risk-loving: Early-life disasters and CEO behavior," The Journal of Finance, 2017, 72 (1), 167-206.

Blanc, Julia Le, Fabian Kindermann, Monika Piazzesi, and Martin Schneider, "Learning about housing cost: Survey evidence from the German house price boom," Work in progress, 2020.

Bruno, Valentina and Hyun Song Shin, "Cross-border banking and global liquidity," Review of Economic Studies, 2014, 82 (2), 535-564.

Brutti, Filippo and Philip Sauré, "Repatriation of debt in the euro crisis," Journal of the European Economic Association, 2016, 14 (1), 145-174.

Caballero, Ricardo J and Alp Simsek, "A model of fickle capital flows and retrenchment," Journal of Political Economy, forthcoming.

Cesa-Bianchi, Ambrogio, Andrea Ferrero, and Alessandro Rebucci, "International credit supply shocks," Journal of International Economics, 2018, 112, 219-237.

_, Luis Felipe Cespedes, and Alessandro Rebucci, "Global liquidity, house prices, and the macroeconomy: Evidence from advanced and emerging economies," Journal of Money, Credit and Banking, 2015, 47 (S1), 301-335. 
Cetorelli, Nicola and Linda S Goldberg, "Follow the money: Quantifying domestic effects of foreign bank shocks in the great recession," American Economic Review, 2012, 102 (3), 213-18.

Chaney, Thomas, David Sraer, and David Thesmar, "The collateral channel: How real estate shocks affect corporate investment," American Economic Review, 2012, 102 (6), 2381-2409.

Cvijanović, Dragana, "Real estate prices and firm capital structure," Review of Financial Studies, 2014, 27 (9), 2690-2735.

Davis, Morris A and Stijn Van Nieuwerburgh, "Housing, finance, and the macroeconomy," Handbook of Regional and Urban Economics, 2015.

Dehos, Fabian and Lea Eilers, "The effect of refugee accommodation on the local housing market," Manuscript, 2018.

Doerr, Sebastian, "Collateral, reallocation, and aggregate productivity: Evidence from the US housing boom," Working Paper, 2018.

Dustmann, Christian, Kristine Vasiljeva, and Anna Piil Damm, "Refugee migration and electoral outcomes," Review of Economic Studies, forthcoming.

Eckert, Fabian, Conor Walsh, and Mads Hejlesen, "The return to big city experience: Evidence from Danish refugees," Working Paper, 2018.

Favara, Giovanni and Jean Imbs, "Credit supply and the price of housing," American Economic Review, 2015, 105 (3), 958-92.

Favilukis, Jack and Stijn Van Nieuwerburgh, "Out-of-town home buyers and city welfare," Working Paper, 2017.

_, David Kohn, Sydney C Ludvigson, and Stijn Van Nieuwerburgh, "International capital flows and house prices: Theory and evidence," Housing and the Financial Crisis, 2013.

_, Sydney C Ludvigson, and Stijn Van Nieuwerburgh, "The macroeconomic effects of housing wealth, housing finance, and limited risk sharing in general equilibrium," Journal of Political Economy, 2017, 125 (1), 140-223.

Flavin, Marjorie and Takashi Yamashita, "Owner-occupied housing and the composition of the household portfolio," American Economic Review, 2002, 92 (1), 345-362.

Forbes, Kristin J and Francis E Warnock, "Capital flow waves: Surges, stops, flight, and retrenchment," Journal of International Economics, 2012, 88 (2), 235-251.

Gan, Jie, "The real effects of asset market bubbles: Loan-and firm-level evidence of a lending channel," Review of Financial Studies, 2007, 20 (6), 1941-1973.

Giroud, Xavier and Holger M Mueller, "Firm leverage and regional business cycles," NBER Working Paper No. 25325, 2018.

Gopinath, Gita, Şebnem Kalemli-Özcan, Loukas Karabarbounis, and Carolina VillegasSanchez, "Capital allocation and productivity in South Europe," Quarterly Journal of Economics, 2017, 132 (4), 1915-1967. 
Hale, Galina and Maurice Obstfeld, "The Euro and the geography of International debt flows," Journal of the European Economic Association, 2016, 14 (1), 115-144.

Hoffmann, Mathias and Iryna Stewen, "Holes in the Dike: The global savings glut, U.S. house prices and the long shadow of banking deregulation," Journal of the European Economic Association., forthcoming.

Hsieh, Chang-Tai and Peter J Klenow, "Misallocation and manufacturing TFP in China and India," Quarterly Journal of Economics, 2009, 124 (4), 1403-1448.

Iacoviello, Matteo, "House prices, borrowing constraints, and monetary policy in the business cycle," American Economic Review, 2005, 95 (3), 739-764.

Jordà, Òscar, Moritz Schularick, and Alan M Taylor, "Macrofinancial history and the new business cycle facts," NBER macroeconomics annual, 2017, 31 (1), 213-263.

Khwaja, Asim Ijaz and Atif Mian, "Tracing the impact of bank liquidity shocks: Evidence from an emerging market," American Economic Review, 2008, 98 (4), 1413-42.

Kiyotaki, Nobuhiro and John Moore, "Credit cycles," Journal of Political Economy, 1997, 105 (2), 211-248.

Laposa, Steven and Mark Charlton, "European versus US corporations: A comparison of property holdings," Journal of Corporate Real Estate, 2002, 4 (1), 34-47.

Larrain, Mauricio and Sebastian Stumpner, "Capital account liberalization and aggregate productivity: The role of firm capital allocation,” Journal of Finance, 2017, 72 (4), 1825-1858.

Liu, Zheng, Pengfei Wang, and Tao Zha, "Land-price dynamics and macroeconomic fluctuations," Econometrica, 2013, 81 (3), 1147-1184.

Maggio, Marco Di and Amir Kermani, "Credit-induced boom and bust," Review of Financial Studies, 2017, 30 (11), 3711-3758.

Martin, Alberto, Enrique Moral-Benito, and Tom Schmitz, "The financial transmission of housing bubbles: Evidence from Spain,” Working Papers, 2018.

Mayda, Anna Maria, Chris Parsons, Hannah Pham, and Pierre-Louis Vezina, "Refugees and foreign direct investment: Quasi-experimental evidence from US resettlements," CEPR Discussion Paper 14242, 2019.

Mian, Atif, Amir Sufi, and Emil Verner, "How do credit supply shocks affect the real economy? Evidence from the United States in the 1980s," NBER Working Paper No. 23802, 2017.

Müller, Andreas, "Die Organisation der Aufnahme und Unterbringung von Asylbewerbern in Deutschland: Working paper/Bundesamt für Migration und Flüchtlinge,” 2013.

Nam, CW and PFJ Steinhoff, "The role of volunteers in German refugee crisis and their contribution to the local government expenditure," CESifo Working Paper No. 7352, 2018.

Nelson, Theron R, Thomas Potter, and Harold H Wilde, "Real estate assets on corporate balance sheets," Journal of Corporate Real Estate, 2000, 2 (1), 29-40. 
OECD, "How are refugees faring on the labour market in Europe?," Working Paper, 2016.

_ , "Land-use planning systems in the OECD: Country fact sheets," 2017.

Pesaran, M Hashem, Time series and panel data econometrics, Oxford University Press, 2015.

Rey, Hélène, "Dilemma not trilemma: The global financial cycle and monetary policy independence," Proceedings, Jackson Hole, 2013.

Rochdi, Karim, "The risk of real estate ownership: evidence from German equities," Journal of European Real Estate Research, 2015, 8 (2), 107-129.

Saiz, Albert, "The geographic determinants of housing supply," Quarterly Journal of Economics, 2010, 125 (3), 1253-1296.

Schmalz, Martin C, David A Sraer, and David Thesmar, "Housing collateral and entrepreneurship," Journal of Finance, 2017, 72 (1), 99-132.

Schmidt, Stephan and Ralph Buehler, "The planning process in the US and Germany: a comparative analysis," International Planning Studies, 2007, 12 (1), 55-75.

Tumen, Semih, "The economic impact of Syrian refugees on host countries: Quasi-experimental evidence from Turkey," American Economic Review, 2016, 106 (5), 456-60.

Uribe, Martin and Stephanie Schmitt-Grohé, Open economy macroeconomics, Princeton University Press, 2017.

Wooldridge, Jeffrey M, "On estimating firm-level production functions using proxy variables to control for unobservables," Economics Letters, 2009, 104 (3), 112-114. 


\section{A Online Data Appendix}

Table A.1 Definitions AND SOURCES Of ALL VARIABLES

\begin{tabular}{|c|c|c|c|}
\hline Variable & Definition & Unit & Source \\
\hline RREP & City c's residential real estate price index, deflated by state-level CPI & $2008=100$ & Bulwiengesa \\
\hline CREP & City c's commercial real estate price index, deflated by state-level CPI & $2008=100$ & Bulwiengesa \\
\hline Non-Developable Area & City c's water bodies, agricultural land and urban open space relative to total built-up area & $\%$ & IOER Monitor \\
\hline Refugees & 2008 share of refugees allocated by the government to city $c$ relative to all refugees in 2008 & $\%$ & Fed. Stat. Off. \\
\hline Exposure & City c's product of the share of refugees and the share of non-developable area & $\%$ & Authors' calculation \\
\hline Share 25-30 & City c's share of people aged 25-30 in total population & $\%$ & INKAR \\
\hline$\triangle G D P$ & City c's growth in GDP per capita, deflated by state-level CPI & $\%$ & INKAR \\
\hline Pop. Dens. & City c's number of inhabitants per square kilometer & - & INKAR \\
\hline Pop. & City c's population in total German population in 2008 & $\%$ & INKAR \\
\hline GIPS spread & The average of the 10-year government bond spread of Greece, Italy, Portugal, and Spain relative to Germany & $\%$ & FRED \\
\hline Bund & The German 10 -year government bond yield & $\%$ & FRED \\
\hline EONIA & The European interbank market rate & $\%$ & FRED \\
\hline ECB rate & The ECB's monetary policy rate & $\%$ & FRED \\
\hline VIX & The CBOE volatility index & $\%$ & FRED \\
\hline Net Bank Inflows Outside Eurozone & Change in net foreign liabilities outside the Eurozone of German BIS reporting banks & $\%$ of GDP & BIS \\
\hline Net Bank Inflows Inside Eurozone & Change in net foreign liabilities inside the Eurozone of German BIS reporting banks & $\%$ of GDP & BIS \\
\hline Gross Bank Inflows Inside Eurozone & Change in gross foreign liabilities inside the Eurozone of German BIS reporting banks & $\%$ of GDP & BIS \\
\hline Gross Bank Outflows Inside Eurozone & Change in gross foreign assets inside the Eurozone of German BIS reporting banks & $\%$ of GDP & BIS \\
\hline Lending-Deposit Spread & $\begin{array}{l}\text { Lending rate is the interest rate charged by banks on short- and medium-term loans to the private sector. } \\
\text { Deposit interest rate is the interest rate offered by commercial banks on three-month deposits (Line 60P - Line 60L). }\end{array}$ & $\%$ & IMF IFS \\
\hline TS & Firm j's tangible fixed assets (Bureau van Dijk code TFAS) as a share of total assets (TOAS) & $\%$ & Amadeus \\
\hline $\mathrm{TS}_{\text {Industry }}$ & The arithmetic mean of TS by 2-digit NAICS code & $\%$ & Amadeus \\
\hline $\mathrm{TS}_{2008} *$ CREP & Firm j's 2008 tangible assets as a share of total assets inflated by the city-level real commercial real estate price index & $\%$ & Authors' calculation \\
\hline $\mathrm{EQ}$ & Firm j's capital-to-asset ratio (CAPI/TOAS) & $\%$ & Amadeus \\
\hline ROA & Firm j's return on assets (EBIT/TOAS) & $\%$ & Amadeus \\
\hline TA & Firm j's logarithm of total assets (TOAS) & $\ln ($ euro) & Amadeus \\
\hline$\triangle I N T E X P$ & Change in firm j's logarithm of interest expenses over total debt (INTE/LOAN) & $\%$ & Amadeus \\
\hline$\triangle E M P L$ & Change in firm j's logarithm of the number of employees (EMPL) & $\%$ & Amadeus \\
\hline$\Delta K$ & Change in firm j's total fixed assets (FIAS) scaled by total assets (TOAS) & $\%$ & Amadeus \\
\hline$\triangle T F P$ & Change in firm j's logarithm of TFP computed by following Wooldridge (2009) & $\%$ & Amadeus \\
\hline$\Delta L_{i, j, t}$ & Log-difference of the stock of loans of bank $i$ to firm $j$ in quarter-year $t$ & $\%$ & Credit Register \\
\hline Bank Share of Gross Foreign Assets & Bank i's gross foreign assets over total assets & $\%$ & Bundesbank \\
\hline Net Foreign Assets & Bank i's net foreign assets vis-à-vis the euro area over total assets & {$[0,1]$} & Bundesbank \\
\hline Interbank & Bank i's interbank funding-to-deposits ratio & {$[0,1]$} & Bundesbank \\
\hline Capital Ratio & Bank i’s regulatory capital-to-asset ratio & $\%$ & Bundesbank \\
\hline Size & Bank i's logarithm of total assets & $\ln ($ euro) & Bundesbank \\
\hline Liquidity & Bank i's liquid assets over total assets & $\%$ & Bundesbank \\
\hline ROA & Bank i's return on risk-weighted assets & $\%$ & Bundesbank \\
\hline NPL & Bank i's non-performing over total loans & $\%$ & Bundesbank \\
\hline Loans & Bank i's loans over total assets & $\%$ & Bundesbank \\
\hline
\end{tabular}


Table A.2 SUMmaRy STATISTICS FOR ALl VARIABLES USED IN THE EMPIRICAL ANALYSIS (In PERCENT Unless Otherwise Noted)

\begin{tabular}{|c|c|c|c|c|c|c|}
\hline Variable & Observations & Mean & Median & SD & 25 th & 75th \\
\hline RREP & 4456 & 104.84 & 102.09 & 9.94 & 98.05 & 110.14 \\
\hline CREP & 456 & 103.24 & 102.46 & 9.60 & 97.98 & 107.92 \\
\hline Non-Developable Area & 456 & 179.93 & 146.89 & 87.64 & 108.03 & 214.03 \\
\hline Refugees & 456 & 0.45 & 0.27 & 0.56 & 0.15 & 0.52 \\
\hline Exposure & 456 & 57.09 & 44.32 & 48.10 & 24.96 & 79.55 \\
\hline Share $25-30$ & 456 & 7.23 & 7.15 & 1.29 & 6.25 & 8.20 \\
\hline$\triangle G D P$ & 456 & 0.58 & 0.58 & 4.33 & -1.54 & 2.73 \\
\hline Pop. Dens. & 456 & 1510.71 & 1347.25 & 740.40 & 983.20 & 2012.25 \\
\hline Pop. & 456 & 1.32 & 0.92 & 1.22 & 0.59 & 1.52 \\
\hline GIPS spread & 60 & 2.04 & 0.46 & 2.84 & 0.19 & 3.22 \\
\hline Bund & 60 & 3.36 & 3.63 & 1.26 & 2.42 & 4.30 \\
\hline EONIA & 60 & 2.08 & 2.07 & 1.57 & 0.36 & 3.34 \\
\hline $\mathrm{ECB}$ rate & 60 & 2.2 & 2.0 & 1.39 & 1.0 & 3.38 \\
\hline VIX & 60 & 20.95 & 19.34 & 8.39 & 14.90 & 24.99 \\
\hline Net Bank Inflows Outside Eurozone & 60 & -2.08 & -4.28 & 12.31 & -8.52 & 1.96 \\
\hline Net Bank Inflows Inside Eurozone & 60 & -2.32 & -1.17 & 6.05 & -5.33 & 1.06 \\
\hline Gross Bank Inflows Inside Eurozone & 60 & 0.13 & 0.78 & 4.65 & -1.96 & 2.64 \\
\hline Gross Bank Outflows Inside Eurozone & 60 & 2.46 & 2.03 & 6.69 & -1.39 & 4.97 \\
\hline Lending-Deposit Spread & 48 & 2.15 & 2.05 & 0.70 & 1.61 & 2.50 \\
\hline $\mathrm{TS}$ & 72,290 & 38.04 & 29.63 & 32.03 & 8.74 & 65.52 \\
\hline $\mathrm{TS}_{\text {Industry }}$ & 90,483 & 36.41 & 27.09 & 18.53 & 22.35 & 54.36 \\
\hline $\mathrm{TS}_{2008} * \mathrm{CREP}$ & 19,972 & 33.98 & 21.41 & 33.40 & 5.19 & 59.41 \\
\hline EQ & 73,948 & 26.36 & 23.85 & 27.77 & 8.56 & 42.76 \\
\hline ROA & 42,275 & 5.48 & 4.51 & 12.29 & 0.75 & 10.30 \\
\hline $\mathrm{TA}$ & 75,076 & 21.09 & 23.06 & 4.68 & 15.62 & 24.02 \\
\hline$\triangle I N T E X P$ & 27,266 & -0.02 & -0.04 & 1.07 & -0.36 & 0.29 \\
\hline$\triangle E M P L$ & 65,776 & 4.31 & 0.00 & 54.85 & -0.80 & 6.24 \\
\hline$\Delta K$ & 62,043 & 33.44 & 0.04 & 476.42 & -0.24 & 0.65 \\
\hline$\triangle T F P$ & 28,813 & -0.52 & 0.04 & 35.51 & -9.15 & 9.49 \\
\hline$\Delta L_{i, j, t}$ & 723,296 & -2.84 & -0.83 & 63.54 & -7.34 & 2.04 \\
\hline Bank Share of Gross Foreign Assets & 89,651 & 58.07 & 59.82 & 15.74 & 50.23 & 67.78 \\
\hline Net Foreign Assets & 29,606 & 0.0009 & -0.00006 & 0.07 & -0.001 & 0.002 \\
\hline Interbank & 27,338 & 0.0003 & 0.00 & 0.009 & 0.00 & 0.00 \\
\hline Capital Ratio & 28,769 & 18.90 & 17.03 & 14.40 & 14.59 & 20.48 \\
\hline Size & 29,615 & 20.76 & 20.59 & 1.32 & 19.87 & 21.41 \\
\hline Liquidity & 29,615 & 20.91 & 17.06 & 15.33 & 12.62 & 23.32 \\
\hline ROA & 28,583 & 2.12 & 1.99 & 3.46 & 1.56 & 2.49 \\
\hline NPL & 27,344 & 3.90 & 3.30 & 3.85 & 2.05 & 4.89 \\
\hline Loans & 29,610 & 58.52 & 60.23 & 15.80 & 51.01 & 68.17 \\
\hline
\end{tabular}

NoTE. The table reports summary statistics for all variables employed in our analysis. The variable definitions and data sources are in Table A.1. 
Table A.3 Matched vs. Unmatched Firms (In PERCENT)

\begin{tabular}{|c|c|c|c|c|c|c|c|}
\hline Variable & Mean(Matched) & Median(Matched) & SD(Matched) & Mean(Unmatched) & Median(Unmatched) & SD(Unmatched) & t-test of difference \\
\hline $\mathrm{TA}$ & 21.1 & 23.1 & 4.7 & 6.8 & 0.2 & 420.5 & $\mathrm{t}=-69.3$ \\
\hline ROA & 5.5 & 4.5 & 12.3 & 7.2 & 4.8 & 19.1 & $\mathrm{t}=19.3$ \\
\hline EQ & 26.4 & 23.9 & 27.8 & 39.2 & 36.9 & 41.4 & $\mathrm{t}=38.3$ \\
\hline TS & 38.0 & 29.6 & 32.0 & 23.3 & 10.8 & 34.7 & $t=-1610.7$ \\
\hline
\end{tabular}

NotE. This table shows the means, medians and standard deviations for selected firm-level variables for the matched sample of firms and non-matched firms. The variables are the logarithm of total assets, the return on assets, the equity-to-asset ratio and the share of tangible fixed over total assets.

Table A.4 List of Cities And Refugee Share, Land Share, And Exposure in 2008 (IN PERCENT)

\begin{tabular}{|c|c|c|c|c|c|}
\hline Aschaffenburg $(0.2,174.0,30.5)$ & Cottbus $(0.1,231.2,25.9)$ & Fürth $(0.2,164.0,26.4)$ & Kassel $(0.6,82.2,47.9)$ & Mannheim $(0.5,109.7,59.0)$ & Rosenheim $(0.1,165.3,11.2)$ \\
\hline Augsburg $(0.6,140.5,82.3)$ & Darmstadt $(1.0,119.1,122.1)$ & Gelsenkirchen $(0.5,68.3,34.1)$ & Kempten $(0.0,291.3,12.8)$ & Mönchengladbach $(0.4,153.8,56.0)$ & Rostock $(0.3,201.0,56.4)$ \\
\hline Bamberg $(0.1,110.5,9.0)$ & Dessau-Roßlau $(0.1,409.8,33.3)$ & Gera $(0.1,391.7,21.5)$ & $\operatorname{Kiel}(0.4,128.7,53.4)$ & München $(4.0,68.9,273.2)$ & Salzgitter $(0.2,353.2,56.5)$ \\
\hline Bayreuth $(0.2,183.0,28.9)$ & Dortmund $(1.3,97.6,122.9)$ & Hagen $(0.4,107.5,38.6)$ & Koblenz $(0.3,174.3,46.2)$ & Münster $(0.4,280.5,110.1)$ & Schweinfurt $(0.1,115.4,14.5)$ \\
\hline Berlin $(5.3,58.2,309.1)$ & Dresden $(0.4,144.0,60.0)$ & Hamburg $(4.8,113.1,537.3)$ & Krefeld $(0.3,130.3,35.0)$ & Neumünster $(0.2,140.1,22.9)$ & Solingen $(0.2,76.7,14.1)$ \\
\hline Bielefeld $(0.7,143.7,98.6)$ & Duisburg $(0.8,104.5,87.1)$ & $\overline{\operatorname{Hamm}(0.2}, 303.9,61.6)$ & Köln $(1.8,108.6,193.3)$ & Nürnberg $(1.2,87.1,107.6)$ & Stuttgart $(1.3,93.1,123.4)$ \\
\hline Bochum $(0.6,69.6,39.6)$ & Düsseldorf $(1.1,104.5,117.2)$ & Heidelberg $(0.2,157.9,35.8)$ & Landshut $(0.1,226.1,19.1)$ & Offenbach $(0.4,84.6,31.7)$ & Suhl $(0.0,149.6,5.7)$ \\
\hline Bonn $(0.7,71.6,51.5)$ & Eisenach $(0.0,431.2,15.1)$ & Heilbronn $(0.4,244.8,101.7)$ & Leipzig $(0.6,182.2,110.1)$ & Osnabrück $(0.2,118.2,26.7)$ & Trier $(0.2,172.0,32.1)$ \\
\hline Bottrop $(0.1,152.5,20.4)$ & Erfurt $(0.3,428.1,125.8)$ & Herne $(0.2,54.6,12.7)$ & Leverkusen $(0.3,98.4,24.7)$ & Passau $(0.0,199.5,9.0)$ & $\operatorname{Ulm}(0.3,241.5,65.9)$ \\
\hline Braunschweig $(0.2,186.5,43.8)$ & Erlangen $(0.1,177.3,24.1)$ & Ingolstadt $(0.1,252.7,27.4)$ & Ludwigshafen $(0.4,120.9,44.5)$ & Pforzheim $(0.4,119.0,44.9)$ & Wiesbaden $(0.5,202.0,101.2)$ \\
\hline Bremen $(1.1,127.4,145.6)$ & Essen $(1.4,70.4,98.9)$ & Jena $(0.1,270.4,25.2)$ & Lübeck $(0.3,232.6,59.2)$ & Potsdam $(0.2,263.6,59.5)$ & Wilhelmshaven $(0.1,244.6,26.0)$ \\
\hline Bremerhaven $(0.2,164.8,27.8)$ & Flensburg $(0.1,133.1,11.2)$ & Kaiserslautern $(0.1,83.5,7.1)$ & Magdeburg $(0.3,245.8,80.3)$ & Regensburg $(0.2,129.1,23.8)$ & Wolfsburg $(0.2,304.6,55.8)$ \\
\hline Chemnitz $(0.3,184.7,59.9)$ & Frankfurt $(1.7,124.2,207.7)$ & Karlsruhe $(0.5,115.2,62.7)$ & Mainz $(0.4,188.1,78.8)$ & Remscheid $(0.1,97.1,11.8)$ & $\begin{array}{l}\text { Wuppertal }(1.0,95.3,91.3) \\
\text { Würzburg }(0.3,144.2,44.1)\end{array}$ \\
\hline
\end{tabular}

Note. The table lists the 79 urban areas defined as cities both in the national accounts and by Bulwiengesa. The numbers in parentheses are the 2008 values of the share of refugees, of the non-developable area ratio, and of our exposure measure, respectively (in percent). Product of the share of refugees and non-developable area share rounded to one digit. Berlin, Bremen and Hamburg, which are underlined, are the three city-states. Berlin, Hamburg and Munich, in bold font, are the largest German cities and have the three highest values for the share of refugees. 


\section{B Online Robustness Appendix}

Table B.1 THE GIPS SPREAD AND BANK Flows

\begin{tabular}{|c|c|c|c|c|c|c|}
\hline & Country-Level & Country-Level & Country-Level & Country-Level & Country-Level & Bank-Level \\
\hline & $(1)$ & (2) & (3) & (4) & (5) & (6) \\
\hline & Net Bank Inflows & Net Bank Inflows & Gross Bank Inflows & Gross Bank Outflows & Lending-Deposit & Bank Share of \\
\hline & Outside Eurozone & Inside Eurozone & Inside Eurozone & Inside Eurozone & Spread & Foreign Assets \\
\hline \multirow[t]{2}{*}{ Spread $_{t}$} & 0.485 & $0.976^{* * *}$ & -0.026 & $-1.002^{* *}$ & $-0.133^{* * *}$ & $-0.246^{* * *}$ \\
\hline & $(1.086)$ & $(0.330)$ & $(0.339)$ & $(0.404)$ & $(0.041)$ & $(0.030)$ \\
\hline Bank Controls & - & - & - & - & - & Yes \\
\hline Macro Controls & - & - & - & - & - & Yes \\
\hline Bank FE & - & - & - & - & - & Yes \\
\hline Obs & 32 & 32 & 32 & 32 & 32 & 86,129 \\
\hline$R^{2}$ & 0.010 & 0.206 & 0.000 & 0.186 & 0.260 & 0.864 \\
\hline
\end{tabular}

Note. The regressions in this table are the same as in Table 1 in the paper. However, they are based on quarterly data from 2007:Q1 to 2014:Q4. The regression in Column (6) is based on the full sample period of 2000:Q1 to 2014:Q4, but includes the following bank and macroeconomic control variables: bank size (log of total assets), the capital-to-asset ratio, liquid assets relative to total assets, the return on assets, the loan-to-asset ratio and the share of non-performing loans to total loans, as well as real GDP growth and the inflation rate (log change in the CPI consumer index). All variables are defined as in the Data Appendix. Heteroskedasticity-robust standard errors are shown in parentheses. *, ** and ${ }^{* * *}$ indicate statistical significance at the $10 \%, 5 \%$, and $1 \%$ levels, respectively.

Table B.2 Bank Flows, Real Estate Collateral, Firm Credit Access

\begin{tabular}{|c|c|c|c|c|c|}
\hline & (1) & (2) & (3) & (4) & (5) \\
\hline & $\Delta \mathrm{L}$ & $\Delta \mathrm{L}$ & $\Delta \mathrm{L}$ & $\Delta \mathrm{L}$ & $\Delta \mathrm{L}$ \\
\hline Spread $_{t-1} \times \mathrm{TS}_{t-4}$ & $\begin{array}{c}0.013^{* * *} \\
(0.003)\end{array}$ & $\begin{array}{c}0.015^{* * *} \\
(0.003)\end{array}$ & $\begin{array}{c}0.016^{* * *} \\
(0.003)\end{array}$ & $\begin{array}{c}0.014^{* * *} \\
(0.003)\end{array}$ & $\begin{array}{c}0.014^{* * *} \\
(0.003)\end{array}$ \\
\hline Spread $_{t-1} \times \mathrm{EQ}_{t-4}$ & $\begin{array}{l}-0.008^{*} \\
(0.003)\end{array}$ & $\begin{array}{l}-0.004 \\
(0.003)\end{array}$ & $\begin{array}{l}-0.009 \\
(0.003)\end{array}$ & & \\
\hline $\operatorname{Spread}_{t-1} \times \mathrm{ROA}_{t-4}$ & & $\begin{array}{c}-0.047^{* * *} \\
(0.003)\end{array}$ & $\begin{array}{c}-0.045^{* * *} \\
(0.003)\end{array}$ & & \\
\hline Spread $_{t-1} \times \mathrm{TA}_{t-4}$ & & & $\begin{array}{c}0.128^{* * *} \\
(0.003)\end{array}$ & & \\
\hline Firm-Year FE & Yes & Yes & Yes & Yes & Yes \\
\hline Bank-Time FE & Yes & Yes & Yes & Yes & Yes \\
\hline Obs & 568,128 & 410,649 & 410,649 & 387,734 & 512,985 \\
\hline$R^{2}$ & 0.145 & 0.145 & 0.145 & 0.136 & 0.141 \\
\hline
\end{tabular}

NotE. The regressions are based on quarterly data from 2009:Q1 to 2014:Q4. The dependent variable is the log difference in loan volume of bank $i$ to firm $j$ in quarter-year $t$, as in Table 6. In Columns (1)-(3), in addition to Spread $_{t-1} \times \mathrm{TS}_{t-4}$, the specification includes the interactions between the GIPS spread and the firm-level capitalto-asset ratio (Column 1), the firm-level return on assets (Column 2), and firm size measured with the log of total assets (Column 3). Column (4) drops observations for 2009 and 2010, a period in which the government intervened in the credit market via guarantees. Column (5) replaces $T S_{t-4}$ with the 2008 firm-level value of the tangible asset ratios, $T S_{2008}$, without inflating it with commercial property prices. All regressions include bank-quarter and firm-year fixed effects. The standard errors in parentheses are clustered at the bank-firm level. ${ }^{*},{ }^{* *}$ and ${ }^{* * *}$ indicate statistical significance at the $10 \%, 5 \%$, and $1 \%$ levels, respectively. 


\section{Online Model Appendix}

In this section, we present a simple model to rationalize the working of the instrument for real estate prices that we use in the empirical analysis. In particular, we show that, while a higher share of refugees unambiguously leads to higher commercial real estate prices, the impact on residential real estate prices can be ambiguous and depends on parameter values. It is therefore plausible to find empirically that the instrument works well for the commercial sector, while it does not necessarily do so in the residential sector. We model commercial and residential housing following Liu et al. (2013).

Local economy and the city share of refugees We consider a collection of $N$ islands or city economies that are identical except for the city share of refugees. There are two types of agents in the local economy. One is the local resident and the other is the refugee. Residents of a given city $c$ are a continuum of mass $p_{c}$ that can be normalized to 1 without loss of generality, while refugees are a continuum of mass $\pi_{c}$, with $\pi_{c}<p_{c}$. Thus, the total city population is $p_{c}+\pi_{c}$ while the normalized size of total population is given by $1+\frac{\pi_{c}}{p_{c}}$.

Omitting the city subscript $c$ for simplicity, denote the ratio of city refugees to city population by $\kappa$. By construction, we have:

$$
\kappa=\frac{\pi_{c}}{p_{c}}=\frac{\frac{\pi_{c}}{\sum \pi_{c}} \times \sum \pi_{c}}{p_{c}},
$$

where $\sum \pi_{c}$ is the total number of refugees. It is now easy to see that there is a one-to-one relationship between $\kappa$ and the city share of refugees as defined in our empirical analysis, $\frac{\pi_{c}}{\sum \pi_{c}}$, conditional on the total number of refugees, $\sum \pi_{c}$, and the city population, $p_{c}$. In our empirical framework, the city share of refugees $\frac{\pi_{c}}{\sum \pi_{c}}$ varies across cities, while the total number of refugees is fixed at the 2008 national level. Therefore, in the model below, the comparative statistic analysis with respect to $\kappa$, conditional on city-level population $p_{c}$, captures the effects of the variation across cities in the share of refugees.

Local residents Consider a representative household-firm-entrepreneur with preferences

$$
U_{0}=\sum_{t=0}^{\infty} \beta^{t}\left[\log \left(c_{t}\right)+\omega \log \left(h_{t}^{R}\right)\right]
$$


where $\beta$ is the discount rate, $c_{t}$ is consumption, $h_{t}^{R}$ is a flow of residential housing services, and $\omega$ is a parameter that governs the share of residential housing expenditure in total expenditure. Output is produced with the following simple technology

$$
y_{t}=A_{t}\left(h_{t}^{C}\right)^{\alpha}
$$

where $A_{t}$ is the aggregate productivity level, $h_{t}^{C}$ is a flow of commercial real estate services, and $\alpha$ is a parameter that governs the share of commercial housing income in total income.

Residents purchase residential and commercial housing services at the market prices $p_{t}^{R}$ and $p_{t}^{C}$, respectively. Their budget constraint is

$$
c_{t}+p_{t}^{R}\left(h_{t+1}^{R}-h_{t}^{R}\right)+p_{t}^{C}\left(h_{t+1}^{C}-h_{t}^{C}\right)+\frac{b_{t+1}}{R}=y_{t}+b_{t}-T_{t}
$$

where $b_{t}$ is a one-period bond issued by the household-firm-entrepreneurs with an exogenous national interest rate $R=1+r$, and $T_{t}$ is a lump-sum transfer from domestic residents to refugees.

Borrowing is collateralized as follows:

$$
-\frac{b_{t+1}}{R} \leq \phi y_{t}+\phi^{C} p_{t}^{C} h_{t}^{C}+\phi^{R} p_{t}^{R} h_{t}^{R}
$$

where $\left\{\phi, \phi^{R}, \phi^{C}\right\}$ are parameters that govern the tightness of the constraint on different types of collateral. The constraint captures the idea that agents can borrow to purchase residential services, commercial services, or to obtain working capital. We also assume that borrowers are impatient, i.e., $\beta R<1$, so that the borrowing constraint is always binding in the steady state.

The residents maximize utility by choosing $\left\{c_{t}, b_{t+1}, h_{t+1}^{R}, h_{t+1}^{C}\right\}$ subject to the budget and 
collateral constraints. The optimality conditions are, respectively, given by

$$
\begin{aligned}
& \lambda_{t}=\frac{1}{c_{t}} \\
& \lambda_{t}=\mu_{t}+\beta R \lambda_{t+1} \\
& \lambda_{t} p_{t}^{R}=\beta\left(\frac{\omega}{h_{t+1}^{R}}+\lambda_{t+1} p_{t+1}^{R}+\phi^{R} \mu_{t+1} p_{t+1}^{R}\right) \\
& \lambda_{t} p_{t}^{C}=\beta \lambda_{t+1}\left(\alpha A_{t+1}\left(h_{t+1}^{C}\right)^{\alpha-1}+p_{t+1}^{C}\right)+\beta \phi \mu_{t+1} \alpha A_{t+1}\left(h_{t+1}^{C}\right)^{\alpha-1}+\beta \phi^{C} \mu_{t+1} p_{t+1}^{C} .
\end{aligned}
$$

where $\lambda_{t}$ and $\mu_{t}$ are the Lagrangian multipliers for the budget and collateral constraints.

Refugees We assume that refugees are hand-to-mouth agents and, for subsistence purposes, receive a fixed per capita lump-sum transfer from the government (i.e., the residents), $\tau$. Thus, $T_{t}=\kappa \tau$. Furthermore, we assume that a fraction $\gamma<1$ consumes a fixed amount of residential housing services, $\tilde{h}^{R}$, while a fraction $1-\gamma<1$ must consume commercial real estate services, $\tilde{h}^{C}$. For simplicity, we assume that both types of real estate services consumed by the refugees are paid directly by the government without entering market transactions.

These assumptions capture critical features of the German policy framework toward asylum seekers and refugees that we discussed in the paper. First, refugees struggle to integrate in the labor market. In Germany, on average, it takes about 15 years to obtain a rate of employment comparable to that of natives and other immigrants-OECD (2016) and Mayda et al. (2019). Moreover, most of these jobs, are temporary and low-skill, making it difficult to obtain credit and sign leases. For this reason, we do not model the very small portion of refugees, who may be able to rent in the market with wage income. Second, each refugee receives a cash allowance to purchase a subsistence level of consumption goods, including food and clothing. The government also provides shelter, either in kind of accommodation centers and other communal facilities or through vouchers for renting in the market. Since, in the model, both kinds of refugees are hand-to-mouth agents, we abstract from the choice between consumption and housing services of the refugees that rent in the market. Rather, their housing and non-housing consumption expenditures are fixed and will be calibrated to the data.

Real estate supply Given the annual frequency of our empirical analysis and the 5-year length 
of our sample period, we assume that the supply of residential and commercial housing services is fixed. For the same reason, we also assume that the two markets are segmented by zoning and land use regulations. The market clearing conditions for the real estate markets, thus, are:

$$
\begin{aligned}
& h_{t}^{R}+\kappa \gamma \tilde{h}^{R}=H^{R} \\
& h_{t}^{C}+\kappa(1-\gamma) \tilde{h}^{C}=H^{C} .
\end{aligned}
$$

These expressions show that, other things equal, in a city with a larger share of refugees, $\kappa$, there is a smaller supply of commercial and residential real estate services available for residents.

Steady state In the steady state equilibrium, the following holds:

$$
\begin{aligned}
& h^{R}=H^{R}-\kappa \gamma \tilde{h}^{R} \\
& h^{C}=H^{C}-\kappa(1-\gamma) \tilde{h}^{C} \\
& y=A\left[H^{C}-\kappa(1-\gamma) \tilde{h}^{C}\right]^{\alpha} \\
& c=\frac{\Gamma_{1} A\left[H^{C}-\kappa(1-\gamma) \tilde{h}^{C}\right]^{\alpha}-\kappa \tau}{1+r \phi^{R} \frac{\beta \omega}{1-\beta-\beta \phi^{R}(1-\beta R)}} \\
& p^{C}=\frac{\beta[1+\phi(1-\beta R)]}{1-\beta-\beta \phi^{C}(1-\beta R)} \alpha A\left[H^{C}-\kappa(1-\gamma) \tilde{h}^{C}\right]^{\alpha-1} \\
& p^{R}=\frac{\beta \omega}{1-\beta-\beta \phi^{R}(1-\beta R)} \frac{c}{h^{R}} \\
& =\frac{\beta \omega}{1-\beta-\beta \phi^{R}(1-\beta R)+r \phi^{R} \beta \omega} \frac{\Gamma_{1} A\left[H^{C}-\kappa(1-\gamma) \tilde{h}^{C}\right]^{\alpha}-\kappa \tau}{H^{R}-\kappa \gamma \tilde{h}^{R}},
\end{aligned}
$$

where $\Gamma_{1}=\left(1-\phi r-r \phi^{C} \alpha \beta \frac{1+\phi(1-\beta R)}{1-\beta-\beta \phi^{C}(1-\beta R)}\right)$.

We are interested in the differential impact on the local economy of a higher share of refugees. To this end, we conduct a comparative statistics exercise by calculating two critical derivatives, $\frac{d p^{C}}{d \kappa}$ and $\frac{d p^{R}}{d \kappa}$, given by:

$$
\begin{aligned}
& \frac{d p^{C}}{d \kappa}=(1-\alpha)(1-\gamma) \tilde{h}^{C} \frac{p^{C}}{H^{C}-\kappa(1-\gamma) \tilde{h}^{C}}>0 \\
& \frac{d p^{R}}{d \kappa}=p^{R}\left(\frac{\gamma \tilde{h}^{R}}{H^{R}-\gamma \tilde{h}^{R} \kappa}-\frac{\alpha(1-\gamma) \tilde{h}^{C} \Gamma_{1} A\left[H^{C}-\kappa(1-\gamma) \tilde{h}^{C}\right]^{\alpha-1}+\tau}{\Gamma_{1} A\left[H^{C}-\kappa(1-\gamma) \tilde{h}^{C}\right]^{\alpha}-\kappa \tau}\right)
\end{aligned}
$$


From these expressions, it is easy to see that the first derivative is always positive. Intuitively, for a given total supply of commercial real estate services, a higher share of refugees who need space in accommodation centers implies a lower supply to the local economy for other uses and hence a higher price $p^{C}$. In contrast, the sign of the second derivative is ambiguous and depends on parameter values. By assumption, in the residential sector, a higher share of refugees has the same direct negative effect on the net supply to residents as in the commercial sector. However, a higher share of refugees also implies a larger lump-sum transfer from residents to refugees and a lower output due to the lower net supply of commercial real estate, which ultimately leads to a lower consumption and thus a lower valuation of residential real estate prices. In equilibrium, the overall impact of a higher refugee share on residential prices depends on the relative strength of these forces, which in turn depends on parameter values.

Calibration In order to explore the sensitivity of the derivative of residential property prices to the share of refugees, we conduct a simple calibration exercise. We will then vary $\kappa$ and see how this affects the steady state.

Table C.1 CALIBRATiOn: PARAMETER VAlues

\begin{tabular}{llll}
\hline \hline Parameter & Definition & Value & Source and Target \\
\hline$\beta$ & Discount rate & 0.98 & Conventional value \\
$R=1+r$ & Gross interest rate & 1.0082 & Average real ex-post German bond yield (2009-2014) \\
$\omega$ & Ratio of housing to non-housing expenditure & 1.27 & Average share of housing wealth in total asset (2009-2014) \\
$\phi$ & Collateral constraint parameter & 0.2 & Conventional value \\
$\phi^{R}$ & Collateral constraint parameter & 0.2 & Conventional value \\
$\phi^{C}$ & Collateral constraint parameter & 0.2 & Conventional value \\
$\alpha$ & Share of commercial real estate income in total income & $38 \%$ & Share of tangible asset in total assets in Table A.2 \\
$A$ & Technology level & 1 & Normalization \\
$H^{C}$ & Commercial real estate stock & 1 & Normalization \\
$H^{R}$ & Residential real estate stock & 0.92 & Average share of residential land in total built-up land in 2008 \\
$\gamma$ & Share of refugees housed in residential sector & 0.58 & Average across 13 non-city states in Table 2 \\
$\tilde{h}^{R}$ & Refugee residential services & 0.01 & Estimated housing expense for refugee \\
$\tilde{h}^{C}$ & Refugee commercial services & 0.01 & Estimated housing expense for refugee \\
$\tau$ & Fiscal transfer & 0.03 & Estimated total expense for refugee \\
\hline \hline
\end{tabular}

Table C.1 summarizes the calibration. The discount rate, $\beta$, is set to 0.98 , a conventional value at annual frequency. The gross interest rate, $R$, is set to the average level of the German government bond yield between 2009 and 2014, deflated with the average ex-post CPI inflation rate. The share of residential housing expenditure in total expenditure is set to $56 \%$, matching the average share of housing wealth in total assets between 2009 and 2014 from aggregate household balance sheet data from the Bundesbank. For the collateral constraint parameters, $\left\{\phi, \phi^{R}, \phi^{C}\right\}$, 
we choose a homogeneous $20 \%$, a conventional value in the literature. The parameter $\alpha$ is set to $38 \%$, matching the share of tangible assets in total assets as in Table A.2. The technology level, $A$, is normalized to 1 , like the total supply of commercial real estate, $H^{C}$. The total supply of residential real estate services, $H^{R}$, instead, is set equal to the average share of land used for residential purposes in total built-up land from the IOER Monitor in 2008, i.e., $\frac{H^{R}}{H^{R}+H^{C}}=48 \%$. The share of refugees in residential housing, $\gamma$, is set to the average share of refugees housed in independent accommodations across the 13 non-city states in Table 2, i.e., $58 \%$. We then calibrate the residential and commercial housing services taken up by refugees, $\left\{\tilde{h}^{R}, \tilde{h}^{C}\right\}$, and the per capita fiscal transfer, $\tau$, based on information from the German policy framework.

Specifically, we assume that the nominal per capita transfer for non-housing consumption is 354 euros for both types of refugees. ${ }^{39}$ We normalize this nominal value by nominal gross national income per capita in $2008, \frac{354}{\mathrm{GNI}_{2008}}$. We then assume that refugees have the same preferences as local citizens, meaning that their ratio of housing expenditure to non-housing expenditure is also given by $\omega$. Under this assumption, we obtain the total per capita government transfer as $\tau=\frac{354}{\mathrm{GNI}_{2008}} *(1+\omega)$. To get to an estimate of the residential (commercial) stock of housing services absorbed by the refugees, we further assume that the price of housing services consumed by the refugees is a unit of their consumption. Thus, this stock is given by $\frac{354}{\mathrm{GNI}_{2008}} * \omega$, and we have $\left\{\tau, \tilde{h}^{R}=\tilde{h}^{C}\right\}=\{0.03,0.01,0.01\}$.

Simulation Results Figure C.1 plots the steady state value of the endogenous variables as we increase the share of refugees, $\kappa$. Panel A reports results for the baseline calibration described above. Consistent with our theoretical derivations, when the local economy has a larger refugee share, the aggregate fiscal transfer, $T$, increases and both stocks of commercial and residential real estate services are lower. This also translates into a lower consumption and output, with a higher level of commercial real estate prices. In contrast, in the baseline calibration, residential

\footnotetext{
${ }^{39}$ According to the pertinent legislation (AsylbLG), asylum seekers and refugees are entitled to reduced benefits for 15 months, after which they receive a more generous welfare package in line with the German unemployment benefits for natives. For the first 15 months, if accommodated in a reception center, they receive 135 euros per month in addition to food and accommodation provided at the center. If they are in private accommodations, they receive 354 euros to cover living costs, including food but excluding rent that is paid by the government separately. So we are assuming that living expenses, such as food provided by an accommodation center, have the same value as the difference between these two allowances.
} 
Figure C.1 Steady STATE FOR COMPaRATIVE Statistics
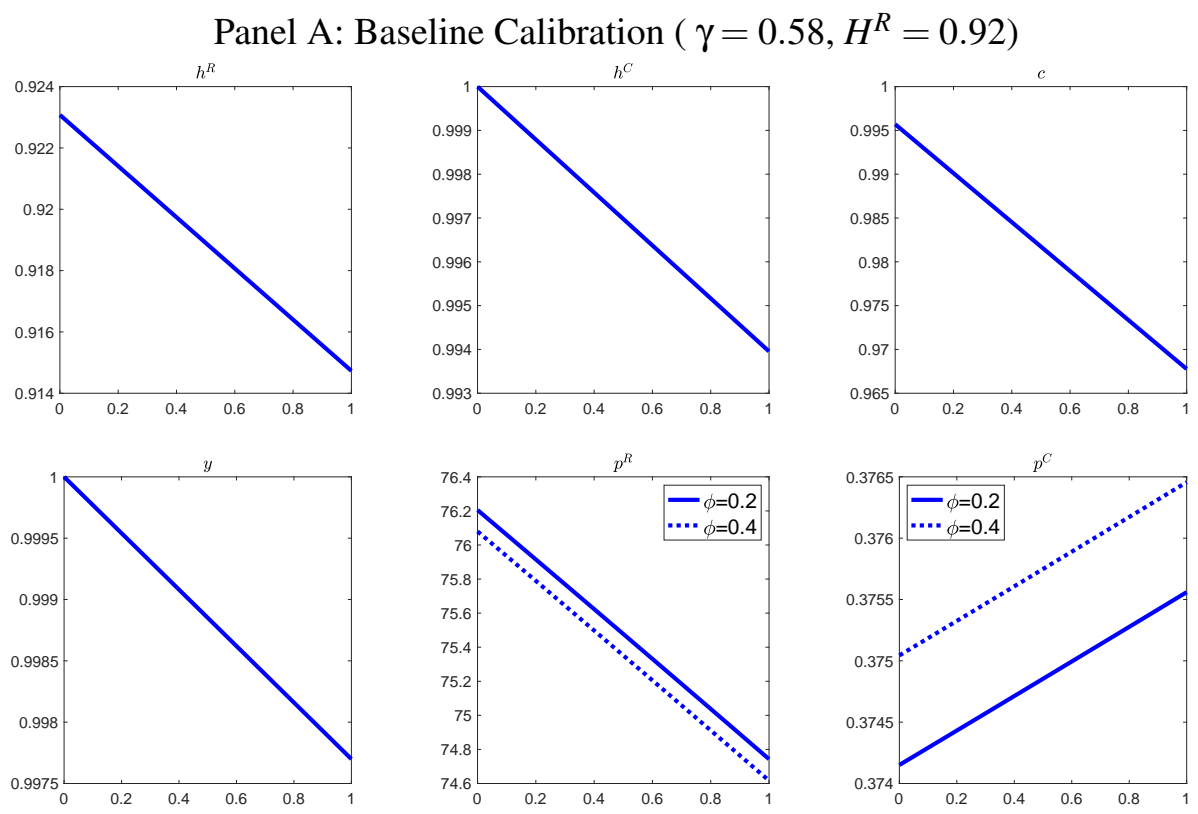

Panel B: Alternative Calibration $\left(\gamma=0.3, H^{R}=0.08\right)$
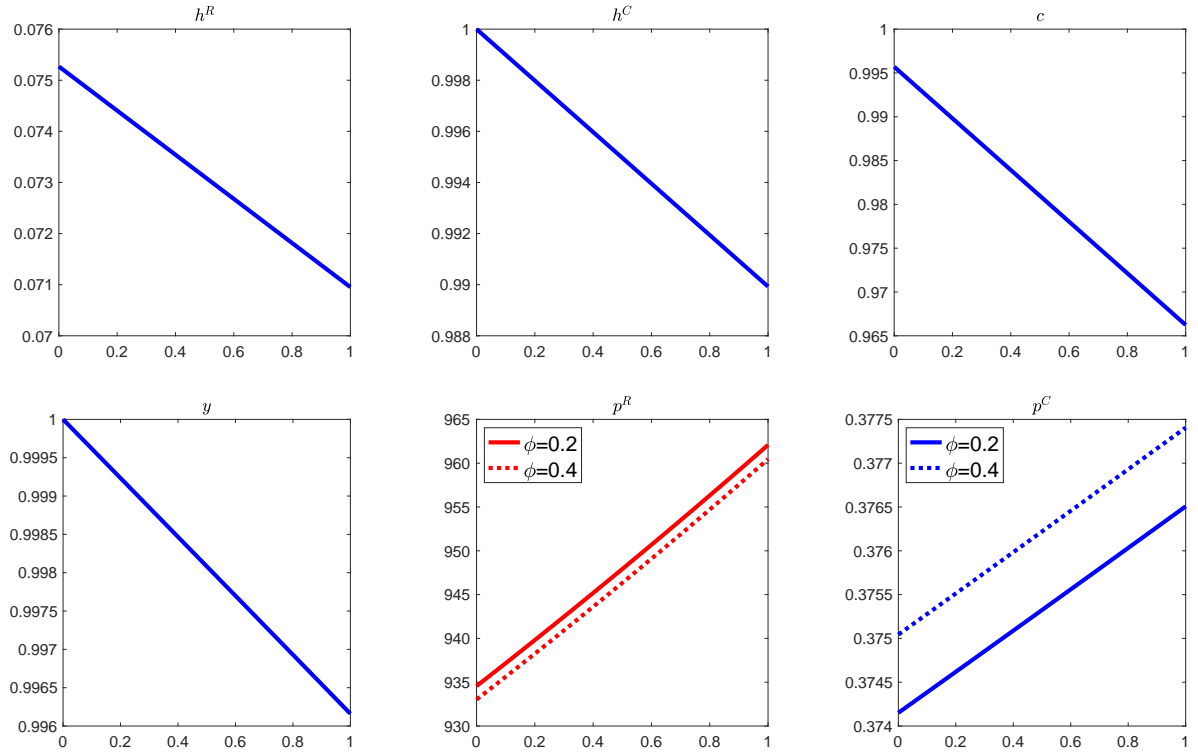

NOTE. The figure reports the comparative statistics of steady state equilibrium variables (y-axis) with respect to a change in the city share of refugees, $\kappa$ ( $\mathrm{x}$-axis). Panel A reports the baseline calibration as in Table C.1. Panel B reports an alternative calibration in which we change only two parameter values, the share of refugee housed in residential sector, $\gamma$, and the stock of residential real estate services, $H^{R}$. Solid lines represent the comparative statistics with the baseline value of the collateral constraint parameter, $\phi=0.2$, while the dashed lines represent a higher value of this parameter, $\phi=0.4$, which can be interpreted as a capital inflow shock. 
real estate prices decrease with a higher refugee share since the effect of lower consumption (due to a lower income and a higher fiscal transfer) dominates the effect of a lower residential housing stock, consistent with our empirical findings on the lack of relevance of our exposure measure for residential property prices.

However, Panel B of Figure C.1 shows that it is also possible to find a model parametrization for which residential prices are higher in cities with higher shares of refugees. For example, here we lower the share of refugees in the residential market, $\gamma$, closer to the value in the three German city states in Table 2. We also set $H^{R}=0.08$, close to the 10th percentile of the 2008 city distribution of the German share of land used for residential purposes in total built-up land, meaning that we consider a city in which the supply of residential services is a much smaller share than the supply of commercial services. Under these two alternative assumptions, a higher share of refugees is associated with higher property prices in both sectors. Indeed, results reported in previous versions of this paper show that our exposure measure would be a relevant instrument also in the residential sector if we were to include the three city states in the analysis.

To see how the share of refugees interacts with the capital flow shock, we conduct a second comparative statics exercise by increasing $\phi$, which loosens the collateral constraint. ${ }^{40}$ The dashed lines in Panel A and B represent the value of the endogenous variables when we increase $\phi$ from the baseline value of 0.2 to 0.4 , a value that is at the upper end of the range used in the literature. The effect of the capital flow shock on property prices seems unambiguous in our model. It increases commercial prices while it decreases residential prices. Furthermore, the capital flow shock does not alter the relationship between the refugee share and real estate prices, suggesting that the capital flow shock is a common factor for property prices in both sectors, while the city share of refugees captures the city variations in housing prices.

As Panels E and F of Figure 1 show, unconditionally, commercial and residential property price are highly correlated in Germany over our sample period, as in the United States, with the commercial sector leading the residential one. Yet, conditional on a capital flow shock, there is no

\footnotetext{
${ }^{40}$ In our simple model, without domestic financial intermediation, an increase in $\phi$ can capture either the credit supply or the credit demand effect of a capital flow shock, as credit supply is assumed infinitely elastic. Here we are assuming that, as we document in the paper empirically, a capital flow shock leads to an increase in domestic credit supply captured by looser collateral requirements.
} 
consensus on the sign of this correlation. For example, Favilukis, Ludvigson and Van Nieuwerburgh (2017) study theoretically the impact of capital flows into the United States and show that lower bond yields associated with capital inflows cannot explain the US residential house price boom. Our model can, in principle, generate a positive or negative conditional correlation, depending on parameter values and how we model investment and the labor market. In the current simple set up without labor and capital, consumption falls with a capital flow shock because the debt service increases with the capital inflow, but output stays the same. However, with the introduction of labor and/or capital into the model, one can see that output would increase. Nevertheless, labor and capital would not detract from the direct impact of the higher refugee share on the net supply of commercial real estate services that drives the relevance of our exposure measure or its components. 